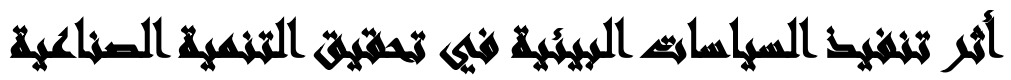

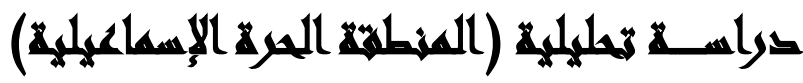

\section{[17]}

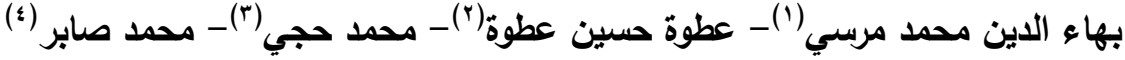

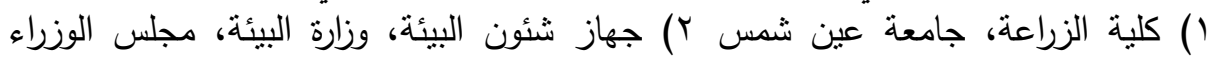

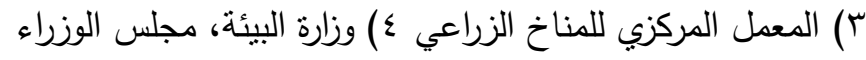

\section{المستخلي}

هدفت الدراسة الى تقييم الدور الفعال الذي تقوم به السياسات البيئية نحو تحقيق التتمية

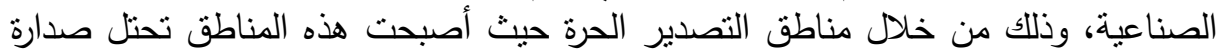

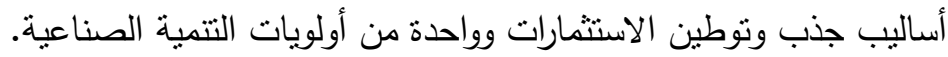

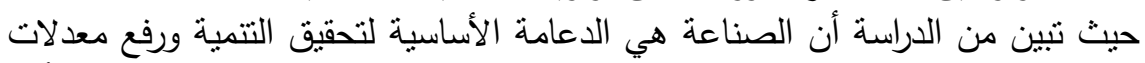

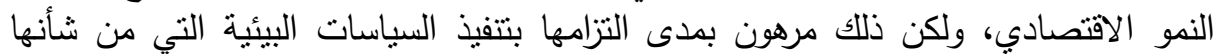
تحقيق التنافسية وإمكانية النفاذ الى الأسواق العان العالمية.

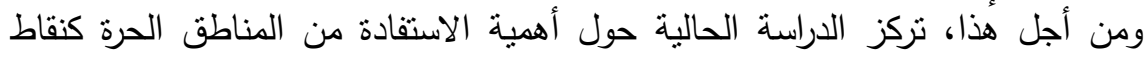

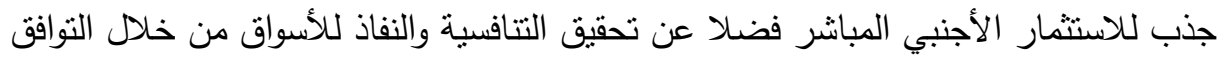

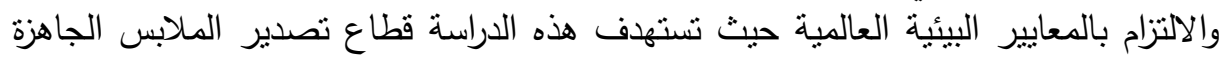

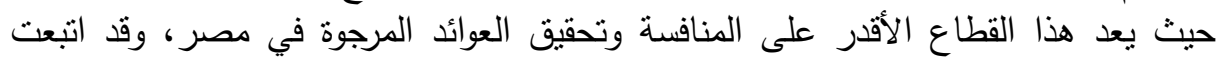

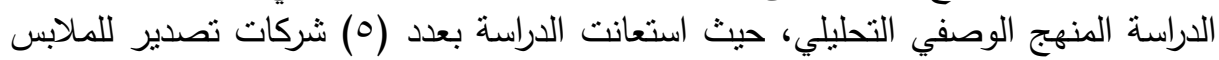

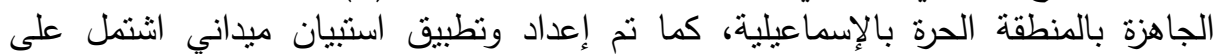

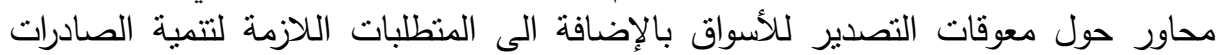
والنفاذ الى الأسواق الخارجية.

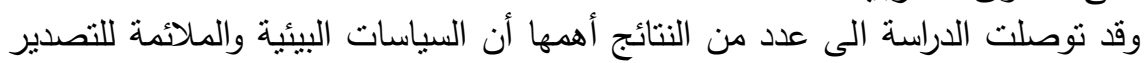

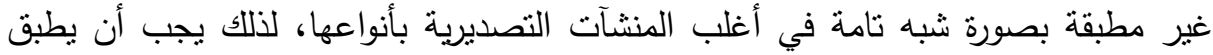

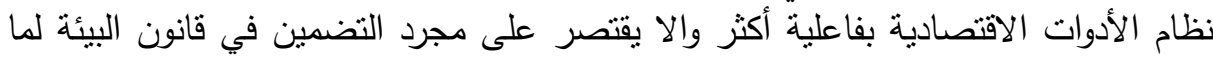

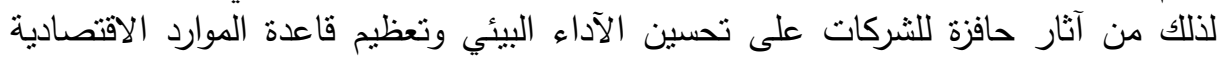

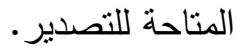

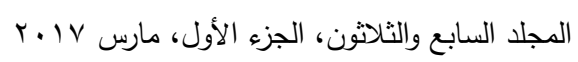




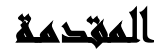

إن تسارع التطور الاقتصادي العالمي يهدف إلى إزالة الحواجز بين الدول وتفعيل روح المنافسة بين المؤسسات والثركات، نتمثل هذه المنافسة في تقديم منتجات وخدمات تتلاءم مع إع رغبات العملاء وتفي باحتياجات المستقيدين. إن هذا الوضع يتطلب ضرورة نطبيق مفاهيم وبرامج إدارية حديثة تتماشى مع هذا النطور السريع وتساعد على رفع مستوى جودة الخدمات والمنتجات مع تخفيض وضبط أكبر في النفقات والتكاليف. ولعل من أبرز الأساليب الإدارية التي ظهرت في الآونة الأخيرة هو أسلوب ستة سيجما والذي يعتبر روئة للجودة حيث تحقق

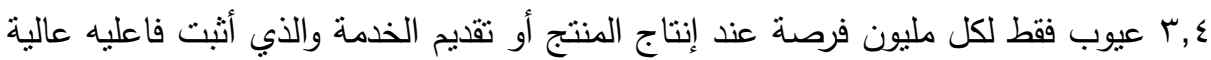
في تطبيقه لاى مجموعة من أبرز الثركات العالمية ولكن مازال تطبيقها يعتبر في المراحل

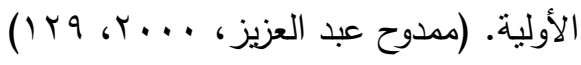

ومن الواضح أن بيئة الأعمال المصرية الصناعية نواجه العديد من المشاكل المعقدة

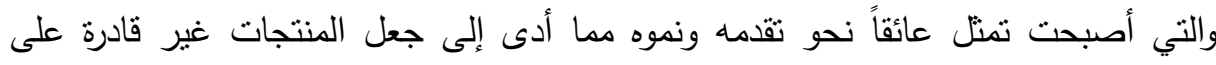
مواجهة منافسة المنتجات الأجنبية سواء في الأسواق المحلية أو الأسواق العالمية.

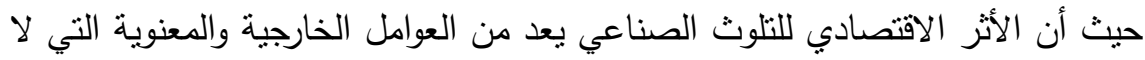

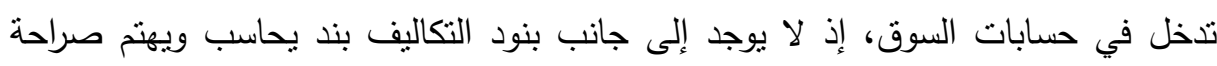

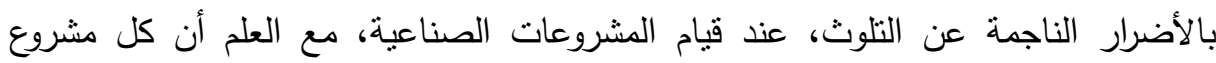

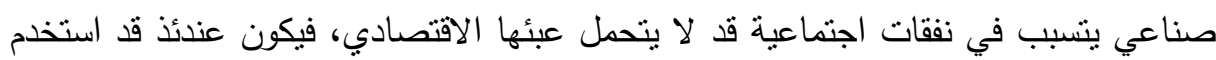
معطيات البيئة مجاناً، وأدى إلى تلويثها دون تعويض اقتصادي، وبالتالي فإن إهمال الآثار

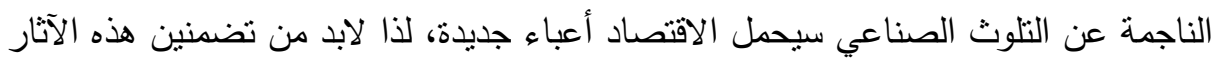
في الحسابات السياسية والاقتصادية لسد الفجوة بين التكلفة الاجتماعية والتكلفة الاقتصادية.

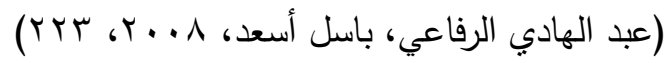

وقد توجهت معظم الدول النامية خلال العقدين الماضيين الى تبنى سياسات وبرامج بيئية تتبثق من استراتيجيات شاملة للتتمية الاقتصادية والاجتماعية، وتراوحت تلك السياسات من كونها مزودة بخطط وبرامج تدار وتتفذ بشكل مباشر ومركزي من قبل الدولة ذات النظام

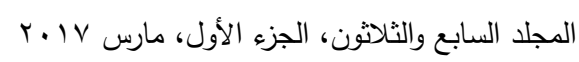


الاقتصادي المركزي، الى كونها مجرد نوجيه لطموحات المؤسسات العامة والخاصة لتتلاءم

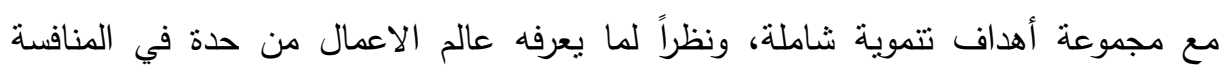

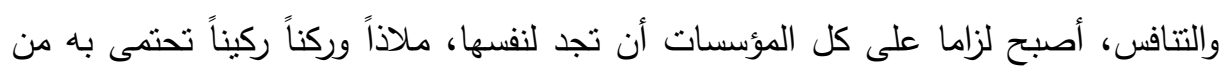
عواصف التغير التي تميز السوق العالمي في هذا العصر، وهو ما يعرف بالتتافسية التي

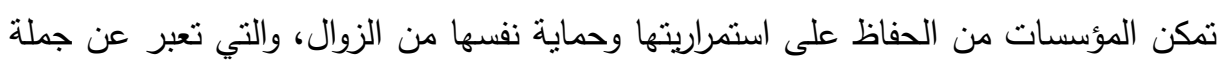

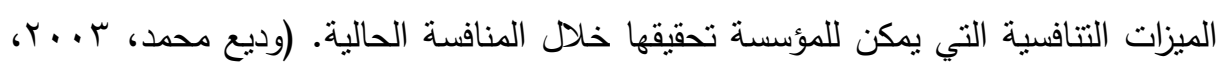

حيث يعتبر البعض أن بقاء واستمرار المؤسسات الصناعية مرهون بالتزامها بتطبيق السياسات البيئية سواء من خلال العمل على دراسة الوضع البيئي للمؤسسة حالياً، وتحول

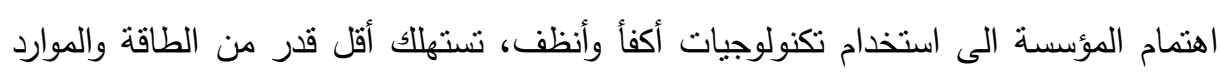

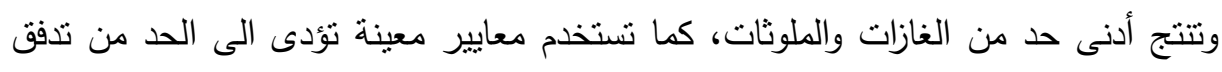

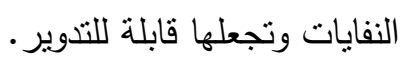

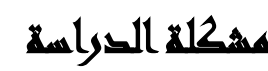

انطلاقاً من هدف السياسات البيئية المنلى التي تسعى لموازنة الفوائد التي تعود على التى التئي

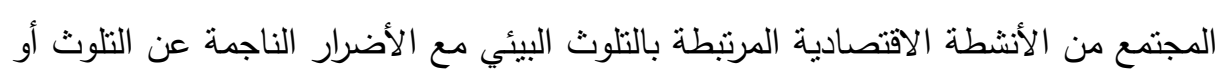

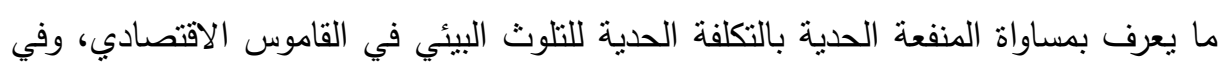

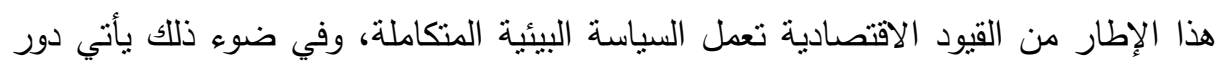
استخدام السياسات البيئية على مستوى الاقتصاد بالنسبة للمنشآت الصناعية في إمكانية

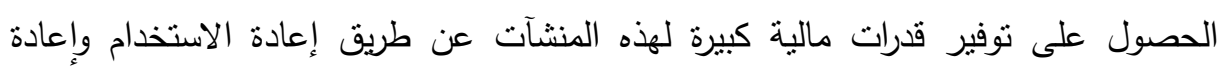

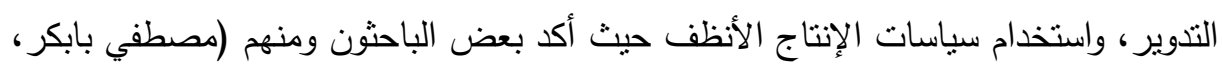

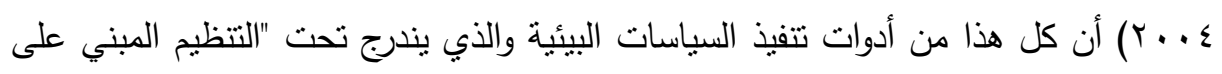

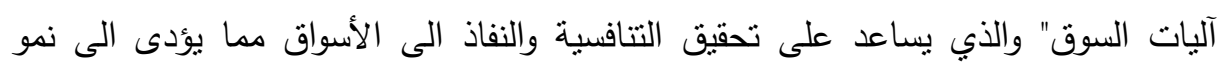

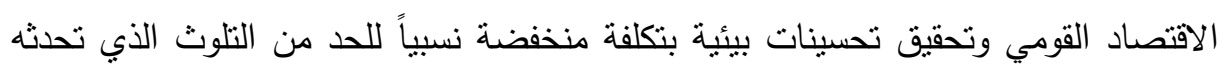
المنشآت الصناعية.

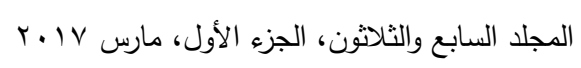


وبالرغم من العلاقة القوية بين تحرير التجارة وحماية البيئة إلا أن بوادر الحساسية بين

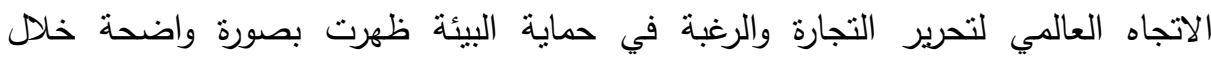

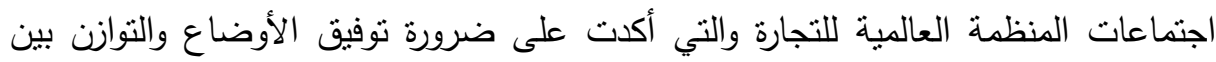
حاجات الدول النامية لاخول أسواق الدول المتقدمة وبين ضعف تتفيذ السياسات البيئية والذي

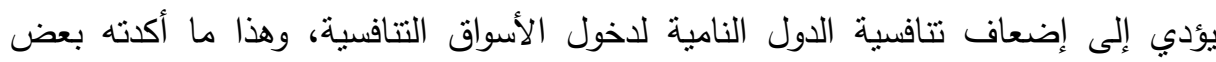

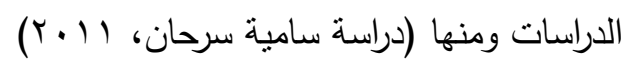

والمشكلة البحثية التي تتعرض لها الدراسة الحالية هي دراسة أثز تتفيذ السياسات البيئية

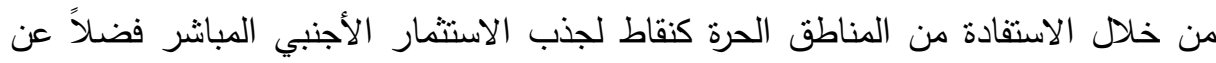
تحقيق التنافسية والنفاذ للأسواق من خلال النوافق والالتزام بالمعايير البيئية العالمية، حيث الثين تستهدف الدراسة قطاع تصدير الملابس الجاهزة حيث يعد قطاع صناعة الملابس الجاهزة

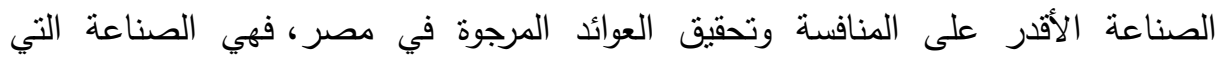
تضمن تحقيق أعلى ربح عن طريق تقليل تكلفة الإنتاج، والاستغلال الأمثل للموارد المتاحة، وكذلك توافر إمكانيات تدعيم قدرتها التنافسية في الأسواق العالمية عن طريق إنى إنتاج السلع المطلوبة وبالكمية المطلوبة في الوقت المحدد وبمسنوى جودة برضى العميل وذلك

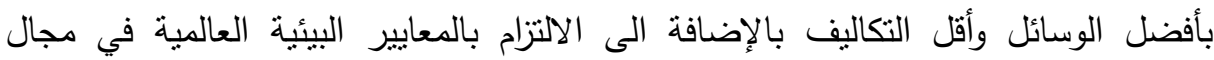
التصدير للأسواق الخارجية.

\section{أسئلا الصوراسلة}

وفى محاولة للتصدي لهذه المشكلة حاولت الاراسة الحالية الإجابة عن الأسئلة التالية:

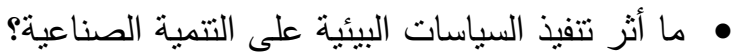

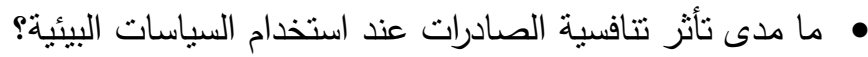
• ما أهم الثروط والمعايير البيئية المتبعة بالنسبة لقطاع التصدير الخاص بالنسيج والملابس

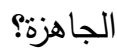
• ما مدى توافق المناطق الحرة مع السياسات البيئية بالنسبة للوضع الراهن؟ 


\section{أهساهث التواسمة}

الهدف الرئيس من الاراسة الحالية هو التعرف على أثر تنفيذ السياسات البيئية في تحقيق التنمية الصناعية. وهذا الهدف يتحقق من خلال الآتي: • تحديد دور وأهمية السياسات البيئية في تحقيق التتمية الصناعية.

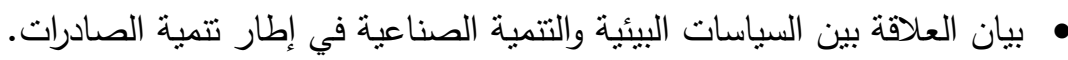

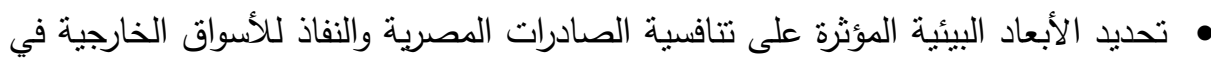

$$
\text { قطاع تصدير الملابس الجاهزة }
$$

• تحديد مدي توافق صادرات الملابس الجاهزة المصرية مع المعايير البيئة العالمية.

\section{هروض التراسمة}

الدراسة في سبيلها إلى تحقيق الأهداف السابقة حيث تقوم باختبار صحة الفروض التالية: ا. توجد علاقة إيجابية ذات دلالة إحصائية بين استخدام أدوات السياسة البيئية وفعالية تتفيذ بلائية

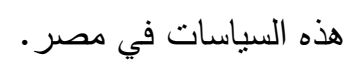

r. توجد علاقة إيجابية ذات دلالة إحصائية بين تنمية الصادرات في مصر وبين تهيئة الظروف البيئية الملائمة.

r. توجد علاقة إيجابية ذات دلالة إحصائية بين الالتزام بالمعايير والاشتراطات البيئية وتتمية الصادرات في مصر · ت اجن

\section{أهمية التصراسما}

تتبع أهمية هذه الدراسة من خلال الأهمية التي تحتلها السياسات البيئية، سواء في كونها دعامة أساسية للنشاط الاقتصادي في الحفاظ على الموارد الطبيعية وترشيد استهلاكها، وأيضاً كونها تلبى احتياجات التتمية الصناعية وذللك من خلال التتافسية والنفاذ للأسواق. الجهات المستفيدة من هذه الدراسة: • وزارة البيئة من خلال العمل على تفعيل الاشتراطات البيئية الدولية المعنية بالتصدير مناه للخارج بالخطط التنفيذية حول حماية البيئة الصناعية.

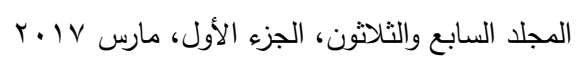


• هيئة التتمية الصناعية من خلال استخدام أدوات السياسات البيئية في تحقيق التتمية

$$
\text { الصناعية. }
$$

• الهيئة العامة للاستثمار والمناطق الحرة من خلال استخدام السياسات البيئية في تحقيق التنافسية والنفاذ للأسواق.

\section{منهمج السواسما}

المنهج الوصفي التحليلي: في دراسة وتجميع البيانات المختلفة حيث يقوم على دراسة

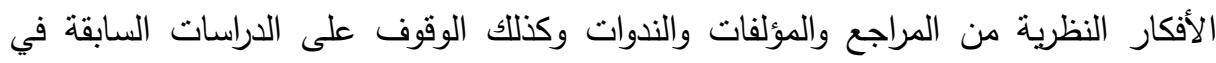
السياسات البيئية والتتمية الصناعية، والتتافسية والنفاذ للأسواق.

\section{هضوض التراسما}

أ- مجتمع الدراسة: شركات تصدير الملابس الجاهزة، المنطقة الحرة - بمحافظة الاسماعيلية

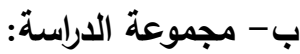

$$
\text { • عدد (0) شركات تصدير للملابس الجاهزة. }
$$

• •شركة أمبى - شركة فيلوسيتى - شركة اوراجلو - شركة البتراء- شركة الخليجية) • عدد •0 ع عامل من العاملين بالمنشآت الصناعية.

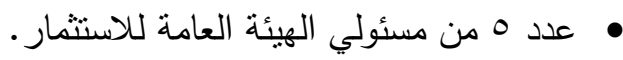

• • ع ع • من مسئولي مكتب البيئة بالمحافظة.

• • • عدد ب من مسئولي هيئة التنمية الصناعية.

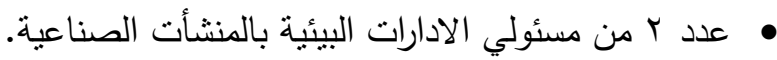

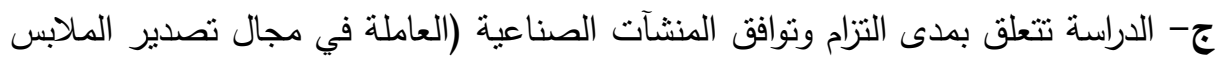
الجاهزة) في المنطقة الحرة -بمحافظة الاسماعيلية بالسياسات البيئية وإمكانية تحقيق التتافسية والنفاذ الى الأسواق في قطاع الصناعة. د- نم تطبيق الاستبيان في العام 1 ـ ـ خ خلال شهر إبريل، مايو ، ويونيه. 


\section{أسوالهي القواسمة}

تمثلت أدوات الدراسة التي استعان بها الباحثون، فيما يلي: • استبيان الغرض منه استطلاع آراء مسئولي العيئة العامة للاستثمار بالمنطقة الحئه الحرة بالإسماعيلية، مسئولي مكتب البيئة بالمحافظة، مديري المنشآت الصناعية، ومسئولي الإدارات البيئية حول مدى نأثثر تتفيذ السياسات البيئية نحو تحقيق التتمية الصناعية. • مقابلات شخصية (لعدد من مسئولي الإدارات البيئية). • معاينات ميدانية للمنطقة وبعض المنشآت الصناعية.

\section{مسطلحاهي القراسها}

• السياسات البيئية: السياسات البيئية إجراءات تتخذ لإدارة الأنشطة البشرية بهدف منع، أو الحد من، أو التخفيف من آثار ضارة على الطبيعة والموارد الطبيعية. (خليل حسين، الطئل ( T r. . T T • التمية الصناعية: هي التتمية التي تولد وتحافظ على صناعة المعرفة ومعلومات السوق

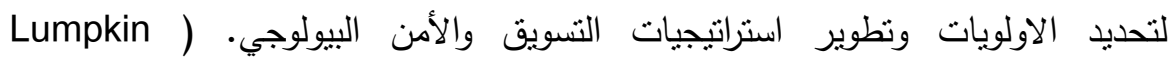
(.G,2001,429 • المناطق الحرة: هي مناطق ضمن إطار حدود الدولة الجغرافية وفي ظل السيادة الكاملة،

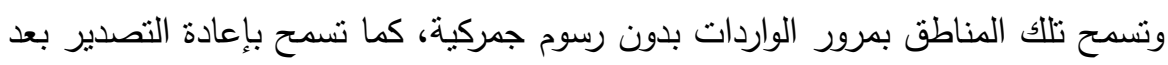

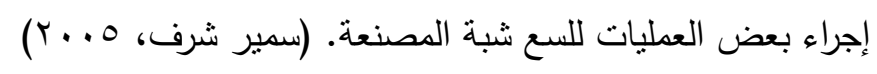

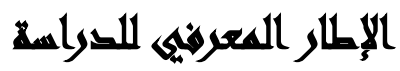

المبحث الأول: البيئة والتلوث والتوازن البيئي

المحور الأول: التلوث البيئي وآثاره: في الآونة الأخيرة زادت الاهتمامات البيئية بعد ظهور

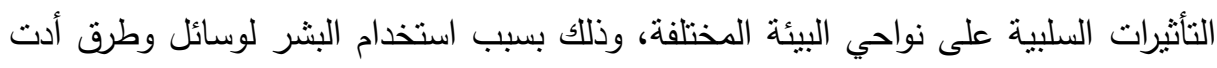

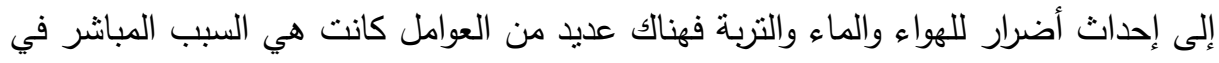

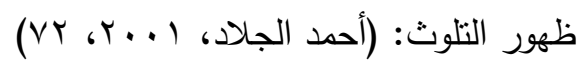

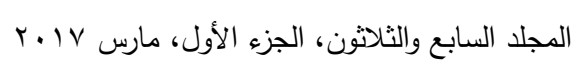


1- أدى التوسع الصناعي في استخدام المنتجات الصناعية إلى زيادة الملوثات في البيئة، كما

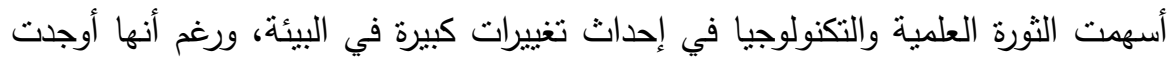

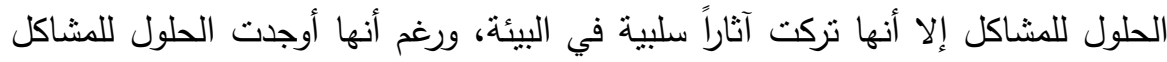

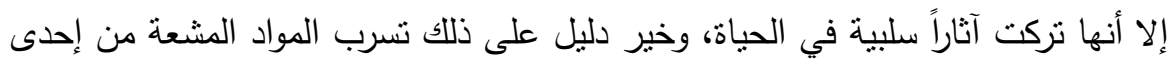
محطات الطاقة النووية في الولايات المتحدة الأمريكية بولاية بنسلفانيا، حيث توقع الدوائر الطبية أن يصاب المتعرضون لهذه الإشعاعات بأمراض خطيرة. r- إن مستويات التلوث ارتقعت بسبب استخدام الآلات المنطورة التي تستخدم الطاقة لتسييرها مما كان السبب المباشر في تلوث الهواء والتربة والماء. وبهذا نجد أن السبب الحقيقي لنلوث البيئة وفقدان توازنها هو سوء استخدام الإنسان لعناصر البيئة ومواردها.

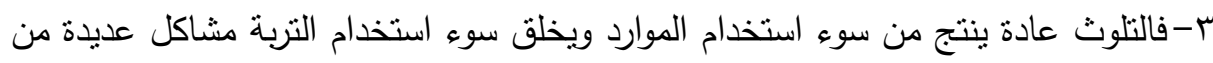
أهمها جرف التربة وتعريتها وما يصاحب ذلك من زيادة فرض إطلاق الملوثات من هذه التربة المعراة. ع-ظاهرة ازدياد عدد السكان ويترتب عليها آثار سلبية عديدة منها نقص الغذاء وأزمة الطاقة، ونقص في الثروات الأخرى، وأخطر ما ينتج عن هذه الزيادة السكانية تلويثها للبيئة التي يعيشون فيها وبخاصة تلك المخلفات والفضلات المنزلية ومخلفات المصانع التي يلقونها.

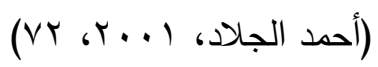

إذن، فالتوسع الصناعي، والانفجار السكاني، وسوء استخدام موارد البيئة، والإنسان صانع النلوث سبب مبانر في تلوث البيئة وفقدان توازنها. ومع مرور الوقت كانت هناء ولات

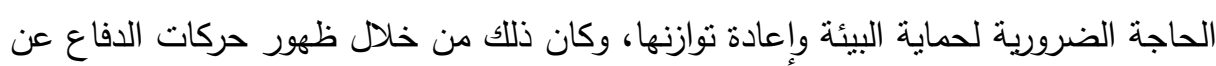
البيئة والتي تسعى للحد من تأثير الإنسان على البيئة.

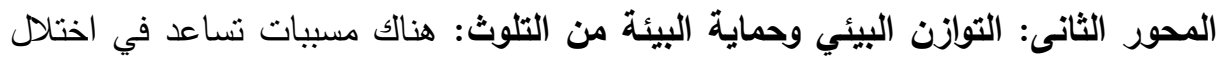

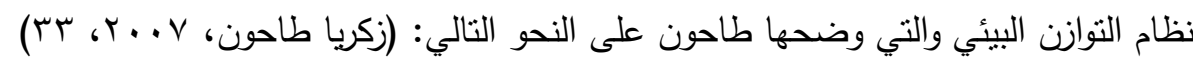
ا. الكيماويات الهيدروكربونية التي تلوث المحيط المائي في وقتتا الحالي ومن أشهرها المنظفات غير القابلة للتفكك والتحلل الحيوي والقاتلة للكائنات الحية. 
r. المخلفات البترولية ومياه التبريد الساخنة الناتجة عن غرق واصطدام ناقلات البترول في

$$
\text { المجاري المائية. }
$$

r. المخلفات الصناعية المحتوية على المركبات الثقبلة (مثل الزئبق والكادميوم وغيره)، ويرجع خطرها في أن الكائنات المجهرية تمنص هذه المواد وتجمعها في جسمها، ثم تتنقل إلى الى أجسام الأسماك التي تتغذى عليها، ثم يتغذى الإنسان على هذه الأسماك ومن ثم يصاب

$$
\text { بالقسم خلال هذه السلسلة الغذائية. }
$$

ع. التلوث بالمواد الصلبة غير القابلة للتفكلك والتحلل الحيوي كالبلاستيك والنايلون وغيرها،

$$
\text { والتي تتجمع باستمرار وتتركز في البيئة وتحل محل مكونات النظام البيئي. }
$$

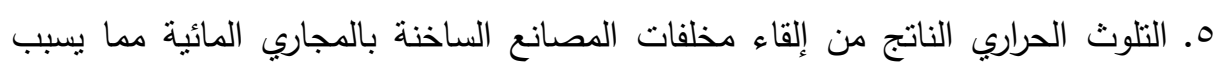

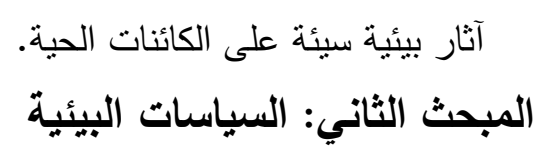

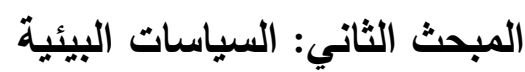

المحور الأول: السياسات البيئية (نشأتها-أدواتها - مدى فعاليتها): مصطلح "السياسات

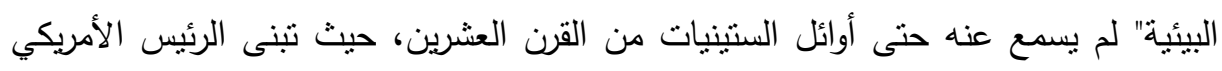

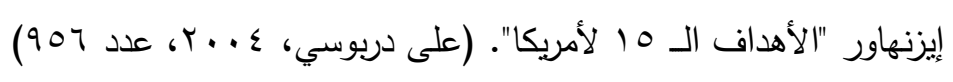

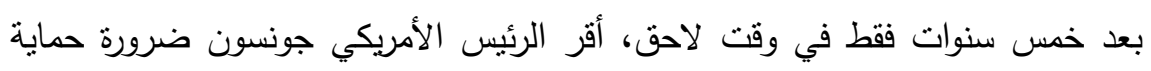

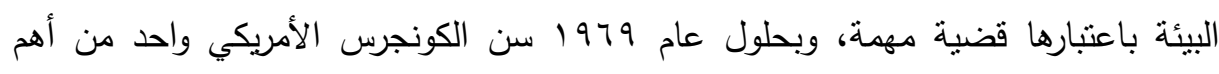

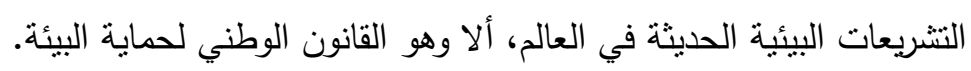

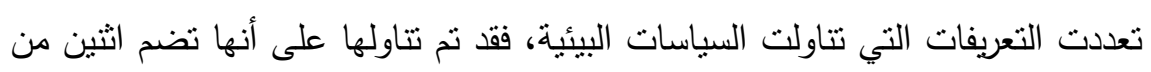

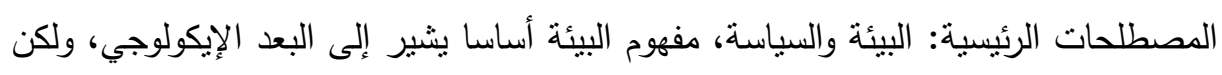
يمكن أيضا أن يراعي البعد الاجتماعي (نوعية الحياة) والبعد الاقتصادي (إدارة الموارد).

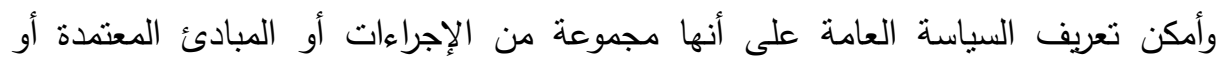
المقترحة من الحكومة أو الحزب أو ورجال الأعمال أو الأفراد. ( Andersen ,M.S (2000,pg337-345

تسعى السياسات البيئية بدورها إلى مساواة الفوائد التي تعود على المجتمع من الأنشطة

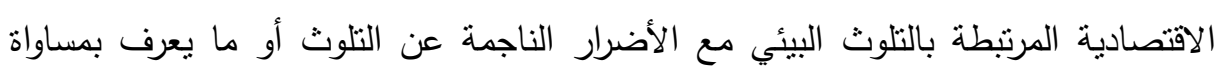

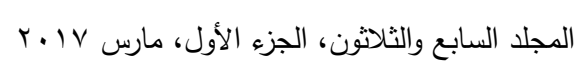


المنفعة الحدية بالتكلفة الحدية للتلوث البيئي (القاموس الاقتصادي) وفى هذا الإطار من القيود

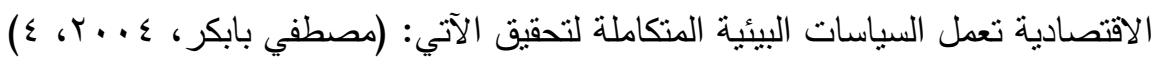

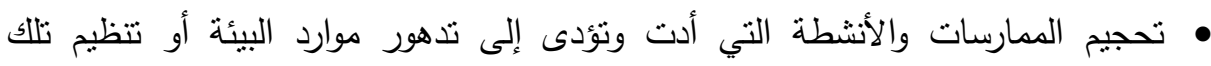
الأنشطة بما يكفل معالجة مصادر التلوث وتخفيف آثاره البيئية قدر الإمكان.

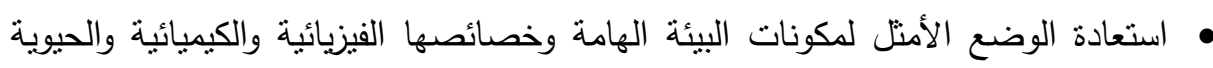
بما يكفل استمرارية قدراتها الاستيعابية والإنتاجية قدر الإمكان.

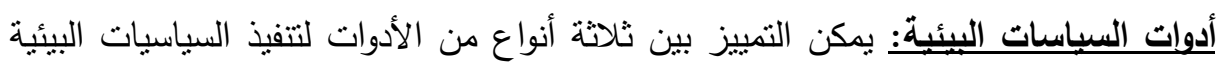

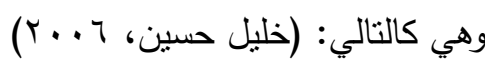
1. الأدوات النعليمية والتثقيفية. r. الأدوات المؤسسية والتشريعية.

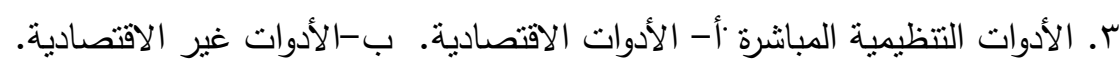

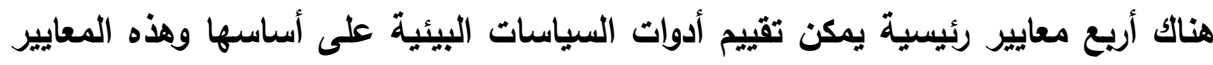

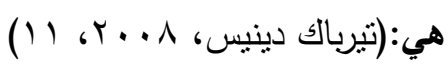
• الفعالية الليئية: أي إلى أي مدى تحقق السياسات البيئية هدفها البيئي أو تحقق نتائج إيجابية على صعيد البيئة.

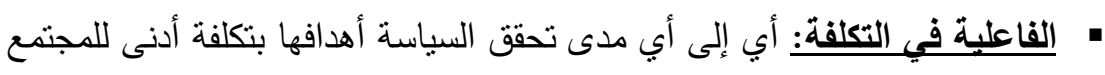

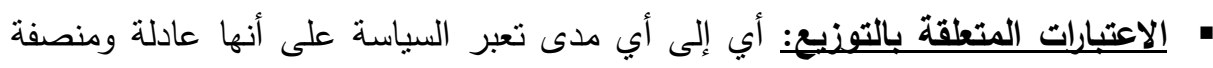

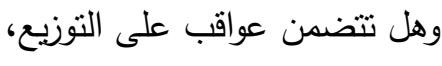
- الجدوى المؤسسبة: أي إلى أي مدى يمكن اعتبار الأداة شرعية ومتوافق عليها ويتم اعتمادها وتطبيقها. المحور الثاني: السياسات البيئية في مصر: كما أولت مصر لحماية البيئة اهنماماً كبيراً حيث أنشأت جهاز شئون البيئة، وتواكب ذلك مع التوجه العالمي في مجال عقد المؤتمرات الدولية المعنية بحماية والحفاظ على البيئة، وكانت مهمة الجهاز الرئيسية هي رسم السياسات

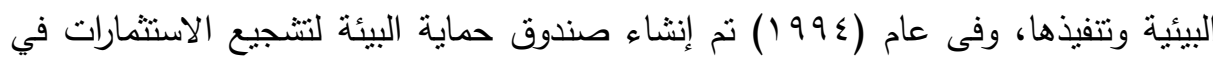


الدجالات البيئية وفى عام (997 (197) تم إنشاء وزارة الدولة لثئون البيئة لتقوم بمراقبة مصادر التلوث ومكافحته ويعاون الوزارة في ذلك بعض الأجهزة المختصة والجمعيات الأهلية العاملة في مجال البيئة.

وتزامن مع ذلك صدور عدد من القوانين والقرارات الهامة المعنية بالبيئة المصرية ومن

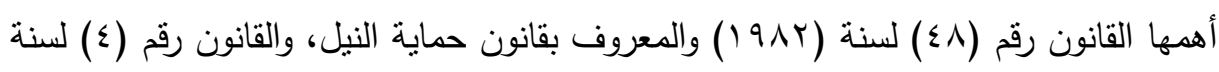

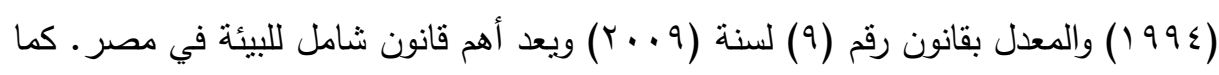
وضعت وزارة الدولة لنشئون البيئة عدة برامج للتحكم في التلوث منها: برنامج مكافحة التلوث،

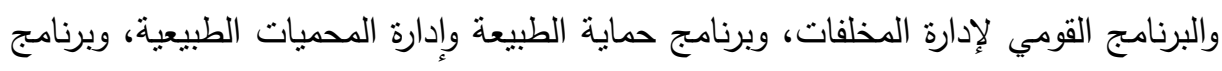

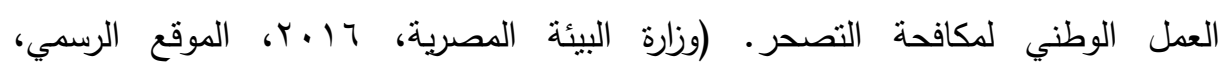

(www.eeaa.gov.eg

\section{المبحث الثالث: انعكاسات السياسات البيئية على التنمية الصناعية}

المحور الأول: العلاقة بين البيئة والتتمية الصناعية: تقوم التتمية الصناعية على استغلال

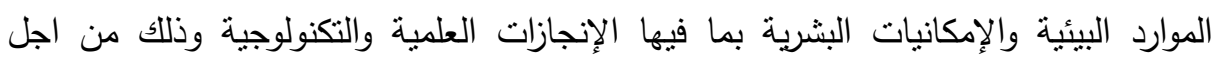
تحقيق عدد من الأهداف أهمها تلبية الاحتياجات البشرية وتحسين وتطوير نوعية حياه البشر ، وحماية البيئة، ويقاس مستوى النهوض والتقدم التتموي في أي مجتمع من خلال التغييرات التي

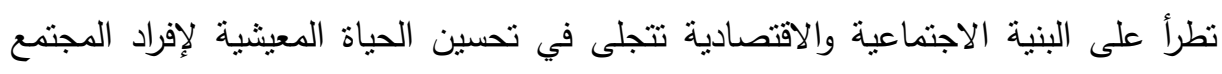
وزيادة الدخل القومي.

من هنا نلاحظ العلاقة الوثيقة بين التتمية الصناعية و البيئة فالأولى نقوم على موارد

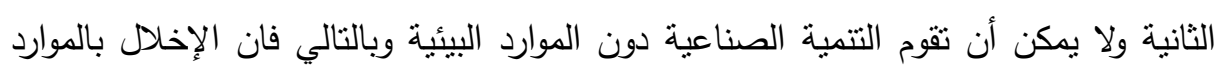

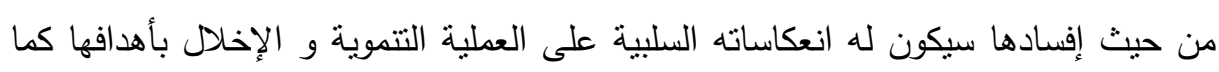

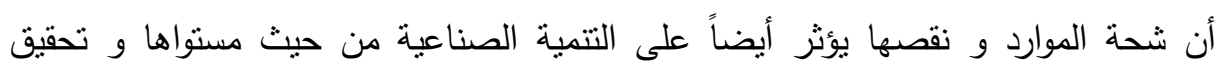

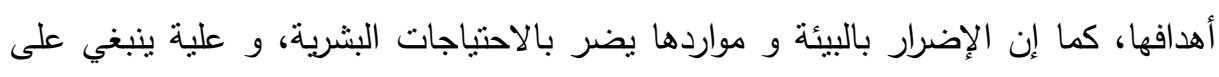

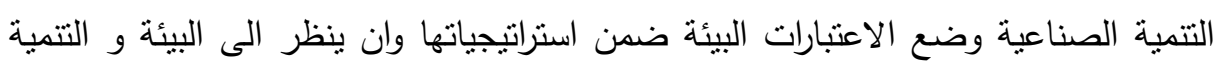

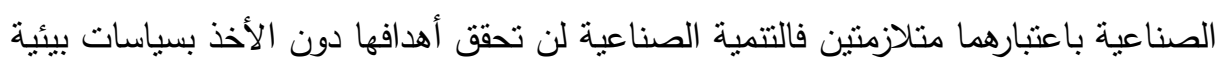

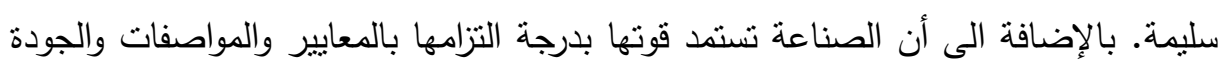

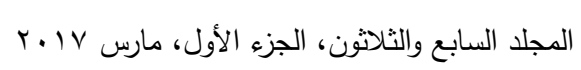


porter . Michael.e,1995,97-( في تصنيع المنتجات التي تتوافق مع المقاييس البيئية.

المحور الثاني: أثر تنفيذ السياسات البيئية في تحقيق التنمية الصناعية: نستمد الصناعة

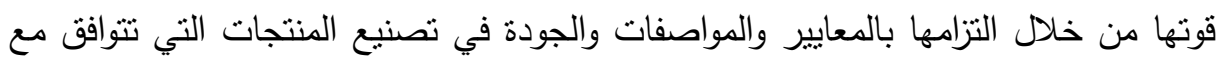
المقاييس البيئية، لذا هناك أهمية لدعم الصناعات الوطنية الملتزمة بالمقاييس البيئية لامتلاكها الوسائل والأدوات التي تناعدها على النمو والاستمرار والمنافسة.

ومن خلال المحاولات لحدوث التغييرات في السياسة الصناعية في الفترة

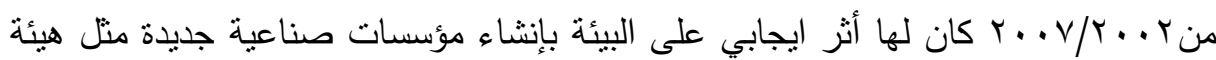
التتمية الصناعية ومركز تكنولوجيا الإنتاج الأنظف، وتنعد هذه التغييرات تطورات إيجابية نحو

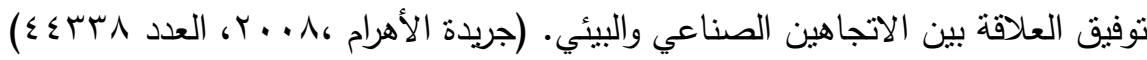
المبحث الرابع: دور السياسات البيئية في تحقيق ميزات تنافسية للمناطق الحرة المحور الأول: الأهية الاقتصادية للصادرات من خلال المناطق الحرة: نشأت فكرة المناطق الحرة منذ زمن بعيد ويرجع ذلك إلى عصر الإمبراطورية الرومانية حيث أقيمت هذه المناطق من اجل جذب التجارة الدولية العابرة وأقيمت في المراكز الرئيسية لخطوط التجارة الدولية، واهتمت في الغالب بتموين السفن وإقامة المخازن وتقريغ وإعادة شحن السلع العابرة ومن أهم الأمنلة للمناطق الحرة (منطقة جبل طارق التي أنشئت عام عـ Vام ومنطقة سنغافورة والتي أنشئت عام 11919 ) ومن أثنهر المناطق الحرة في الوطن العربي منطقة جبل علي في إمارة دبي، وتطورت فكرة المناطق الحرة من حيث الأهداف والمساحة وأماكن الإقامة و الامتيازات

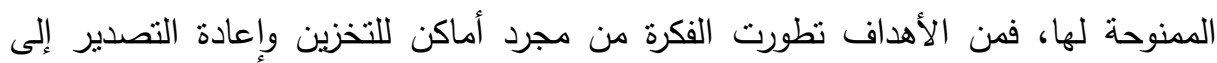
مناطق تقدم العديد من الخدمات في مجال الصادرات او الصناعة ومن حيث إقامتها ومساحتها فبعد أن كانت تقام في مراكز خطوط التجارة الدولية وبمساحات صغيرة أصبحت

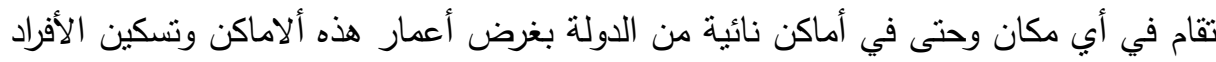

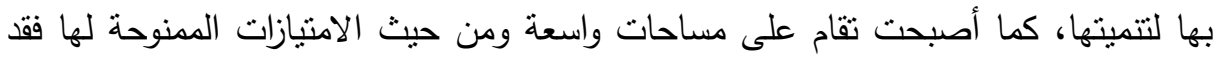

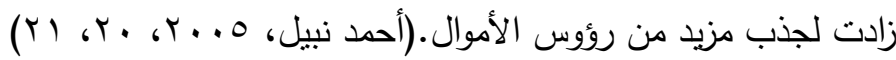


المحور الثاني: مدى تأثير السياسات البيئية على تنافسية صادرات الدول النامية عامه

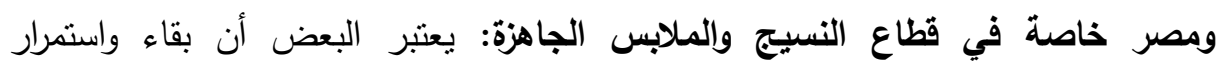

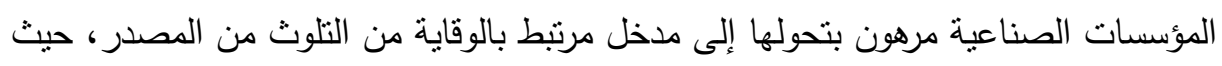

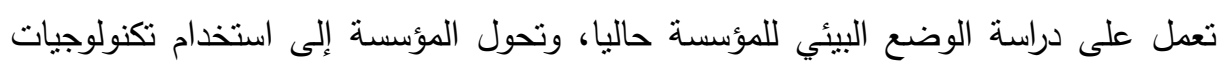

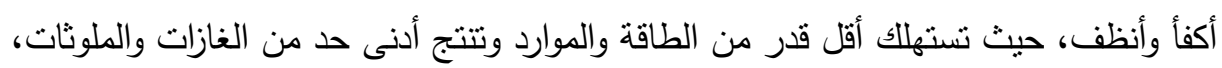

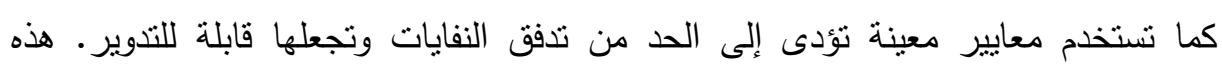
التحولات أو التطورات التكنولوجية تدعو الى التحول إلى الكفاءة البيئية والتي تعرف على على إنها:

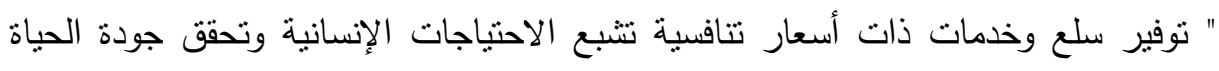

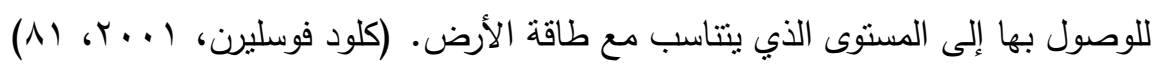

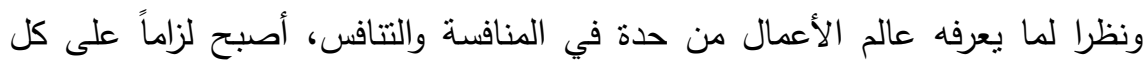

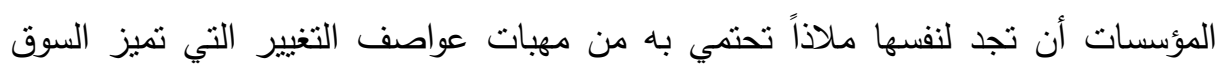

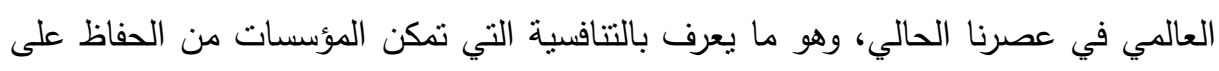

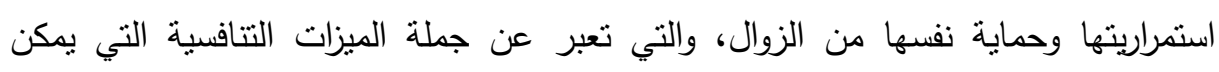
للمؤسسة تحقيقها في سباق المنافسة الحالي. إن معايير الجودة البيئية - خاصة المعايير المرتبطة بالإنتاج والعمليات تمنل إحدى

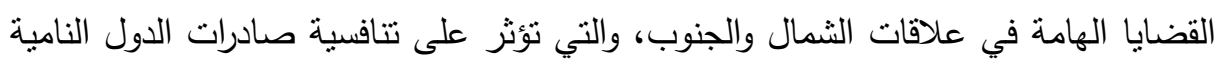
في الأسواق الخارجية حيث أثنارت دراسة (Parikh 93) الى أن تطبيق معايير الجودة البيئية

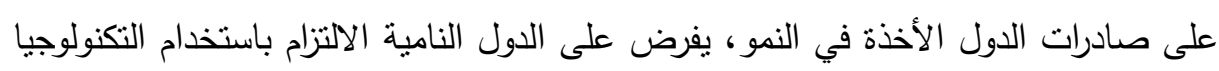

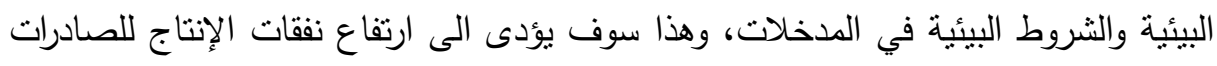

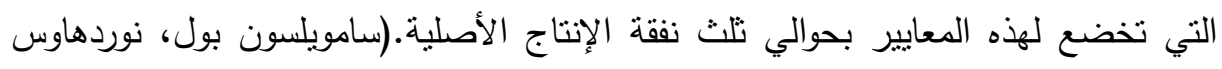

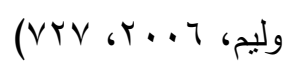




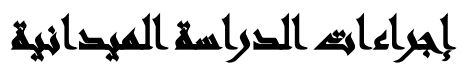

المبحث الخامس: الدراسة الميدانية لشركات تصدير الملابس الجاهزة بالمنطقة الحرة الإسماعيلية: وللإجابة عن أسئلة الدراسة، كان لابد من إعداد استمارة استبيان للشركات الصناعية بالمنطقة الحرة وضبطه، وتطبيقه على السادة العاملين بهذه الثركات بالمنطقة الحرة بالإسماعيلية، وقد تم عمل الآتي:1-استنيان حول مدى التوافق مع المعايير البيئية المطلوبة لتتمية صادرات الملابس الجاهزة والمنسوجات على عينة من الثركات المصدرة بالمنطقة الحرة بالإسماعيلية والجهات

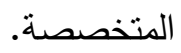

r-تضمن الاستبيان مجموعة من البنود البيئية الرئيسة والفرعية لعينة من الثركات استتد في وضعها على مواصفات الأيزو والمعايير البيئية الاوروبية المشتركة (معايير نوعية البيئة، معايير انبعاث الملوثات، معايير العمليات والإنتاج، معايير المنتجات، معايير الأداء) r-بالإضافة الى مجموعة الاثكال المصورة الخاصة بالثركات محل الدراسة الميدانية. وتم الأخذ بأراء المُحكِّمين والتي تمثلت في حذف بعض الأتسات العبارات وتحويل بعض العبارات من معيار إلى آخر تتنمي إليه كما أضاف البعض منهم عدداً من العبارات وبالتالي أصبح

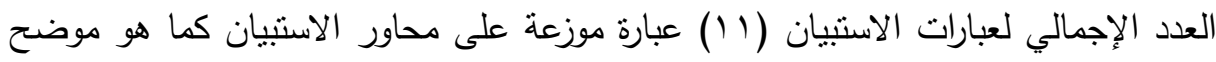
بالجدول رقم (1)، والدرجة الكلية لكل محور ومفردة. 
جدول رقم(1) - عدد العبارات وأرقمها بالاستبيان

\begin{tabular}{|c|c|c|}
\hline أرقام المفردات & عدد العبارات & البـــد \\
\hline 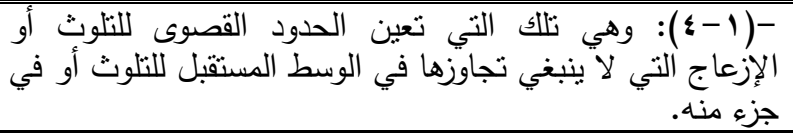 & $r$ & | البيئة \\
\hline 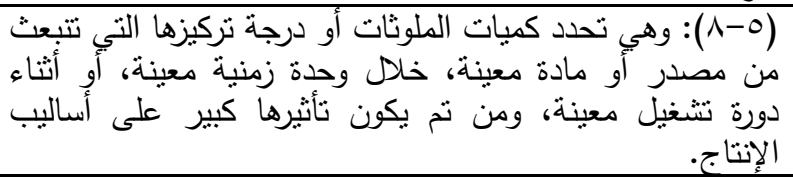 & $r$ & 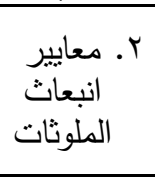 \\
\hline 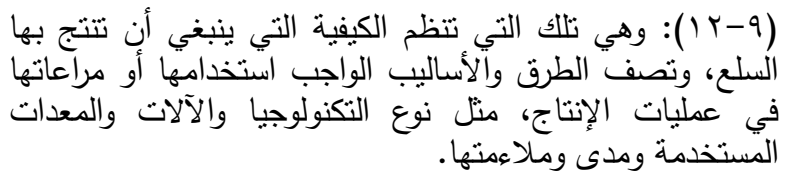 & $r$ & آل العمليات \\
\hline 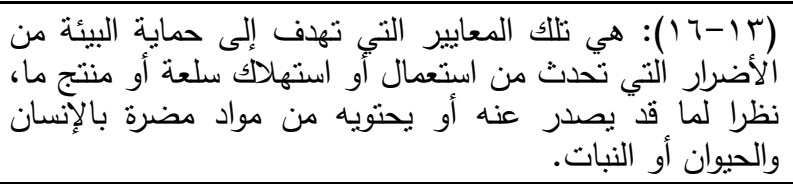 & 1 & 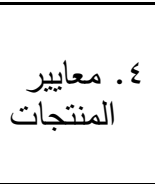 \\
\hline 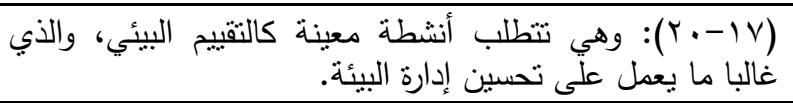 & 1 & 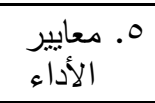 \\
\hline & & المــــــموع \\
\hline
\end{tabular}

بعد الانتهاء من الخطوات السابقة تُعيّن على الباحثون تطبيق الصورة المبئية للاستبيان

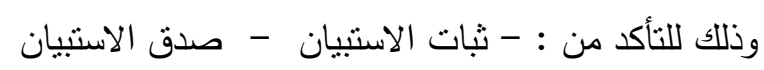

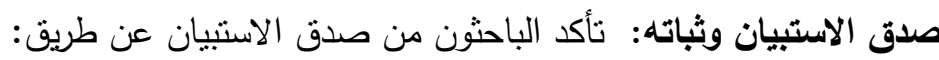

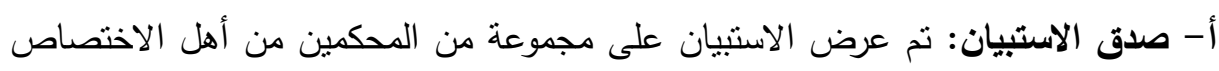

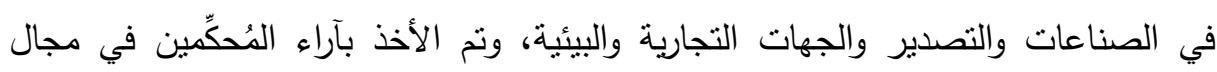

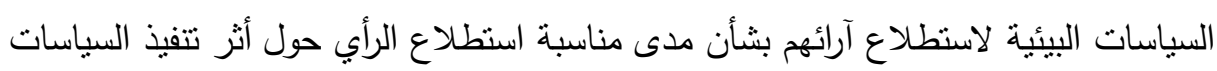
البيئية على التتمية الصناعية، ومدى تأثر تتافسية الصادرات عند استخدام السياسات البيئية،

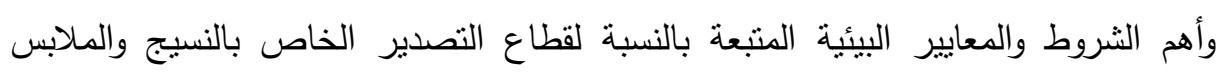

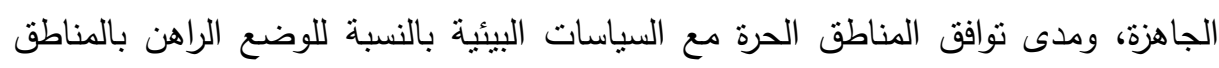

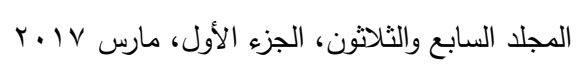


الحرة من حيث صياغة العبارات ومدى تمثيل هذه العبارات لهحاور الاستيان وقد تم مراعاة التوصيات التي أجمع عليها المحكمون. ب -ثبات المقياس: نم النأكد من ثبات المقياس بإنباع طريقة التجزئة النصفية وقد طُبِّق

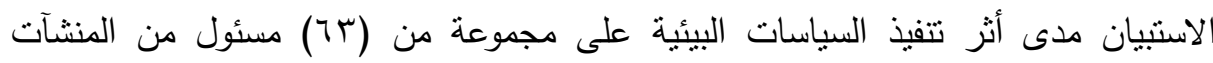

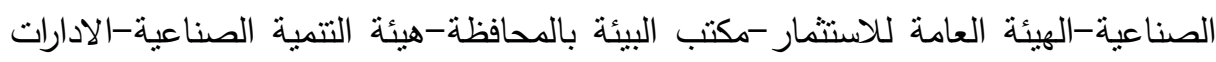
البيئية بالمنشآت الصناعية. وقد تم حساب ثباتهما باستخدام معامل كرونباخ - ألفا (Cronbanch-Alpha) وكانت

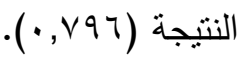
حساب ثبات الاستبيان(اسنطلاع الرأي) حول مدى تأثير السياسات البيئية على التتمية الصناعية للعينة الاسنطلاعية وفق معامل ألفا كرمباخ: عeliability Statistics-

\begin{tabular}{|c|c|}
\hline Cronbach's Alpha & عدد آفراد العينة \\
\hline$\cdot, \vee \vee 97$ & $\pi$ \\
\hline
\end{tabular}

وبذلك يكون الباحتون قد أتموا إعداد أداة الدراسة وضبطها والتحقق من صلاحيتها

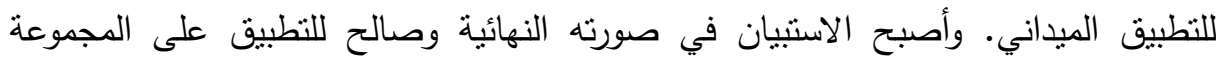
المختارة من العاملين بالصناعة والتصدير للملابس الجاهزة والمنسوجات بالمنطقة الحرة بالإسماعيلية قوامها، ... وأجريت هذه الدراسة في عام 17 . ب خلال الفترة من أول شهر إبريل إلى شهر يونية،

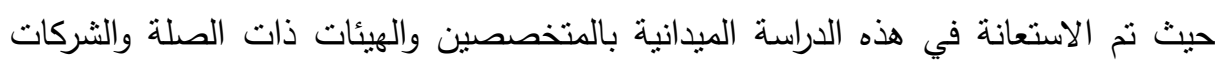
المصدرة للملابس الجاهزة في المنطقة الحرة بالإسماعيلية. 


\section{نمائي التراسلة}

أولاً: نتائج اختبار الفروض: أظهرت نتائج اختبار الفروض (معامل الإرتباط -

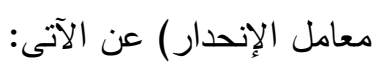

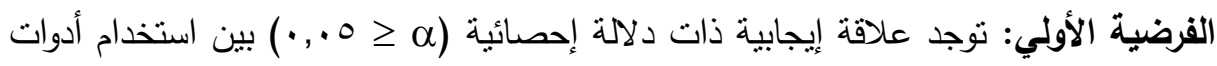

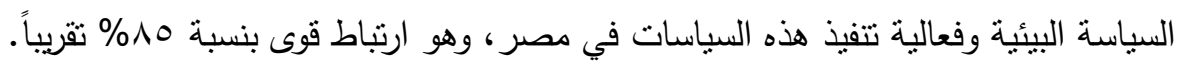

\section{ونتج عن هذه الفرضية تحقق العناصر التالية:}

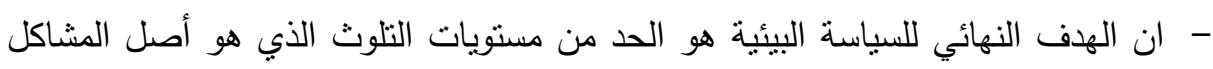

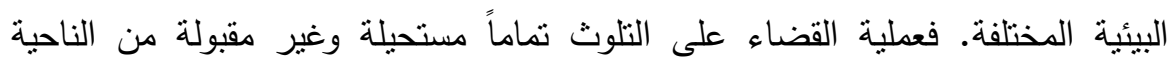

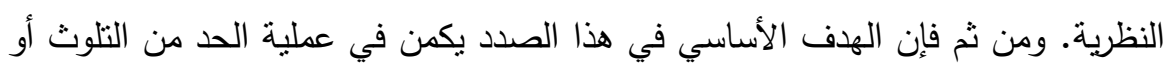
الوصول إلى الحجم الأمثل والمقبول اقتصادياً.

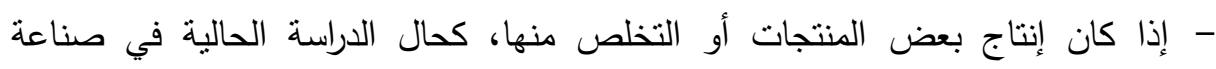

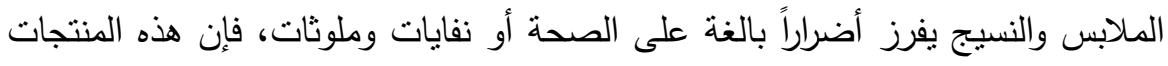

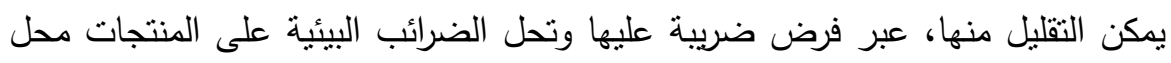

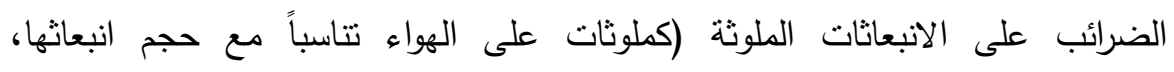

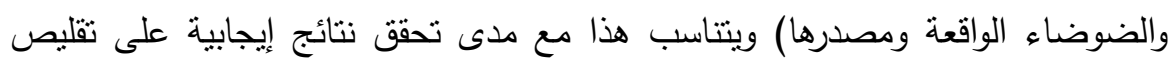

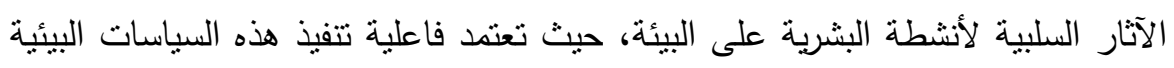

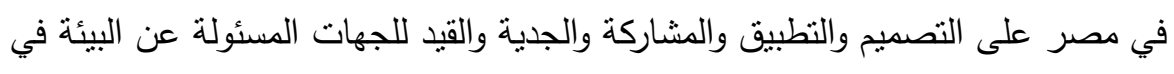
مصر.

- أن فعالية التكلفة في تنفيذ السياسات البيئة في مصر بأتي من خلال تحقق السياسة

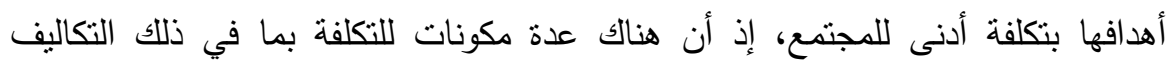

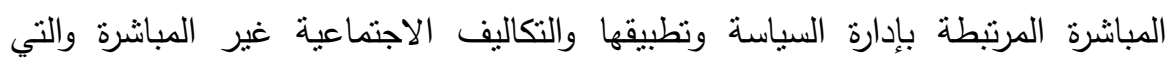

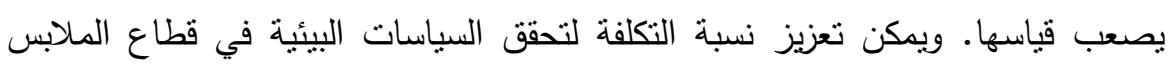

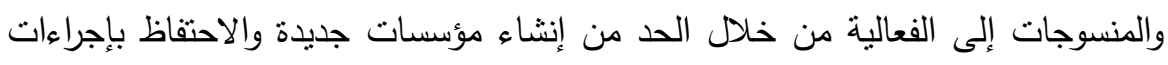
يتم تطبيقها بطرق بسيطة قدر الإمكان اللمؤسسة.

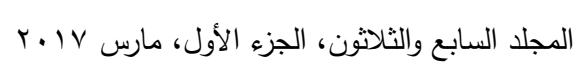


- كلما ازدادت درجة الأضرار البيئية كلما كانت الدولة ربما في حاجة إلى اتخاذ إجراءات

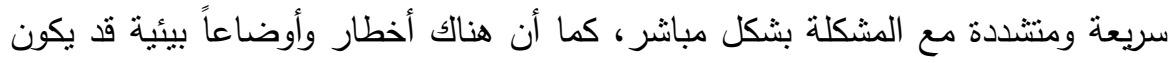

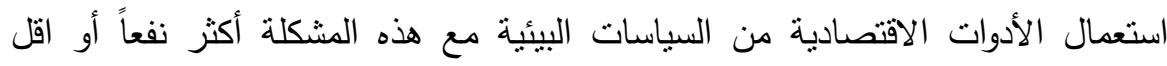

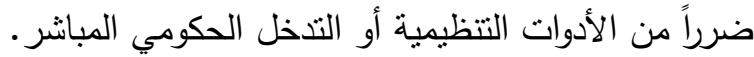

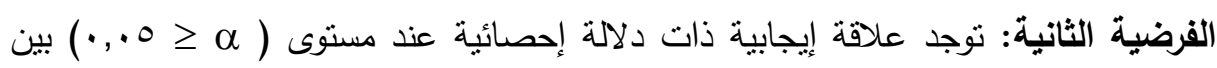
تتمية الصادرات في مصر وبين تهيئة الظروف البيئية الملائمة.

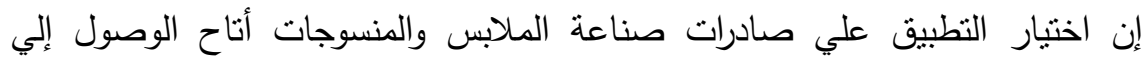
الجوانب الحقيقة لقضية تتمية الصادرات المصرية والأبعاد الاقتصادية والبيئية والاجتماعية المؤثرة عليها، نظرا لعراقة الصناعة وهيمنتها علي الصادرات الصناعية غير النفطية وتمتعها

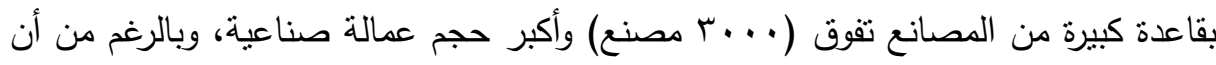

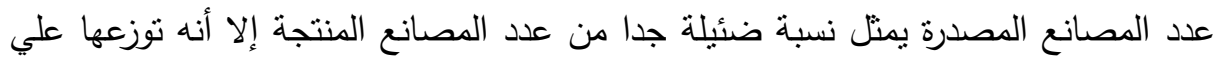
قطاعات مثل المناطق الحرة الصناعية، كان له أكبر الأثر في إثراء النتائج النهائية

للاستقصاء بجانب الآراء الخاصة بالعاملين في الجهات ذات الصلة بالصناعة وصادراتها.

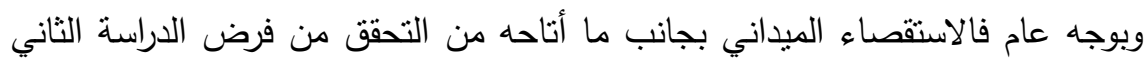
والخاص بنوضيح العلاقة بين تتمية الصادرات في مصر وبين تهيئة الظروف البيئية الملائمة

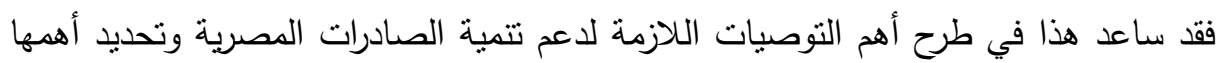
بمشاركة آراء المصدرين (مناطق حرة) والمتخصصين الاستثماريين. وعن مدى الالتزام بالمواصفات والمتطلبات البيئية في قطاع النسيج والملابس الجاهزة باستخدام قوائم المراجعة والفحص البيئي: كان من الضروري لدعم الأبعاد المتعلقة بالتصدير، وللتعرف على أوضاعها داخل شركات العينة (المصدرة للملابس والمنسوجات) مراجعة ددي نوافر ال 1 بند بيئي داخل هذه الثركات بأي نسبة حيث تعتبر هذه البنود مميزة في نماذج الجودة البيئية العالمية وفي المواصفات المختلفة للجودة والتوافق مع البئئة الاقتصادية العالمية الجديدة، كما أنه قد تم تدعيم قائمة الملاحظة والاستقصاء بأثنكال مصورة للبيئة الداخلية والخارجية، وللنواحي التسويقية والإنتاجية داخل هذه الثركات بأنواعها.

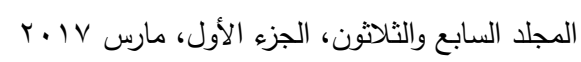


يتتاول الجدول رقم (Y) بالتحليل بعض من مجموعة مفردات وبنود الاستبيان وهي (l') البنود المميزة للجودة البيئية والتي تعنبر من المقومات الرئيسية لقيام أي نظام جودة بيئية فعال

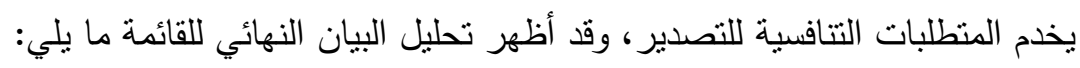

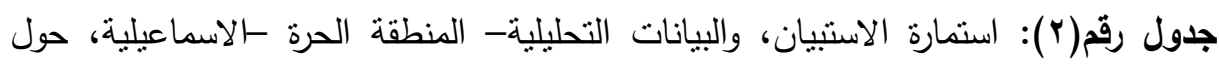
البنود البيئية في شركات العينة

\begin{tabular}{|c|c|c|c|c|c|c|c|c|c|c|}
\hline \multicolumn{2}{|c|}{ الخليجية } & \multicolumn{2}{|c|}{ ش شاكة } & \multicolumn{2}{|c|}{ أوراجللوا } & \multicolumn{2}{|c|}{ فيلوسيتى شركة } & \multicolumn{2}{|c|}{ شركة أمبى } & البنود \\
\hline 牛: 专 & $\frac{2}{9}$ & 눅: & $\frac{9}{9}$ & .4: & $\frac{2}{9}$ & 转: & $\frac{9}{9}$ & 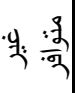 & $\frac{2}{9}$ & \\
\hline 7. & $\varepsilon$. & 0. & 0. & $\varepsilon$. & 7. & r. & $\vee$. & $\varepsilon$. & 7. & الـ وجود حد أدنى من السياسات \\
\hline$\varepsilon$. & 7. & $\varepsilon$. & 7. & r. & $\wedge$. & $\varepsilon$. & 7. & r. & $\vee \cdot$ & التحسينات المستمرة العدارة العليا على إدخال \\
\hline ro & 70 & ro & 70 & $r \cdot$ & $\wedge$. & r. & $\wedge$. & ro & 70 & والجوانب البيئية بعض المظاهر \\
\hline ro & 70 & ro & 70 & 10 & 10 & 10 & 10 & ro & vo & البيئية والقانونية بالالنزام بالمسئولية \\
\hline$\varepsilon$. & 7. & $\varepsilon$. & 7. & ro & vo & ro & vo & $\varepsilon$. & 7. & ه- الاعداد لبرامج بيئية \\
\hline$\varepsilon$. & 7. & $\leq 0$ & 00 & ro & 70 & r. & $\wedge$. & r. & $\vee$. & افراد المنظمةب والتوعية البيئية بين \\
\hline <0 & 00 & ro & 70 & r. & $\wedge$. & r. & $\wedge$. & ro & 70 & 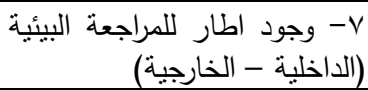 \\
\hline 0 . & 0 . & $\varepsilon$. & 7. & ro & 70 & $\varepsilon$. & 7. & ro & vo & 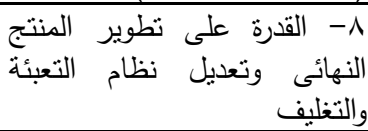 \\
\hline$\varepsilon$. & 7. & ro & 70 & $\varepsilon$. & 7. & ro & vo & $\varepsilon$. & 7. & 9- وجلفات بأنواعها تخطي للسبطرة على \\
\hline$\varepsilon$. & 7. & 00 & $\leq 0$ & 7. & $\varepsilon$. & 0. & 0 . & $v$. & r. & الخارجى القدرق على الحد من التلوث \\
\hline vo & ro & $\checkmark$. & r. & $\varepsilon$. & 7. & $\vee$. & $r$. & 7. & $\varepsilon$. & 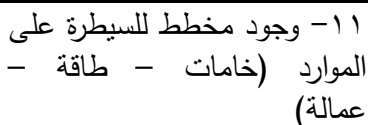 \\
\hline
\end{tabular}




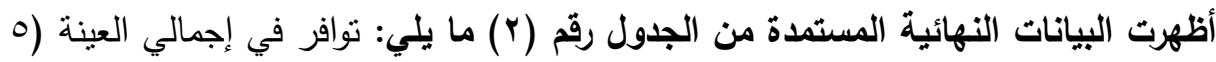

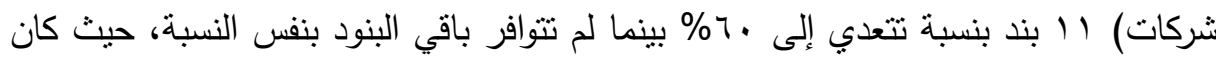
الأساس في تحديد توافر البند هو تواجده بأي نسبة (مقبولة) ولو كانت ضئيلة نسبياً.

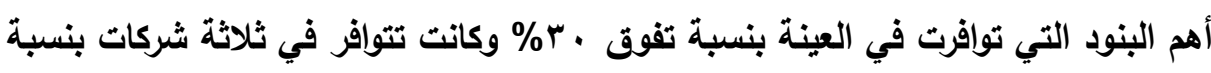

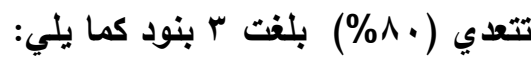
- البند رقم (ץ) الخاص بوجود بعض المظاهر والجوانب البيئية، وقد توافر في إجمالي العينة

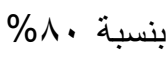

- البند رقم (ع) والخاص التخطيط والالتزام بالمسئولية البيئية والقانونية، وقد توافر بنسبة البهام .\%

- البند رقم (V) والخاص وجود إطار للمراجعة البيئية (الداخلية - الخارجية)، وقد توافر بنسبة .\%^.

- أهم البنود التي لم تتوافر في العينة (0 شركات) بنسبة تصل إلى (0\%) بلغت ب بنود كما يلي: - البند رقم ( ) والخاص بوجود حد أدنى من السياسات البيئية، وكانت نسبة نوافره . 0\%.

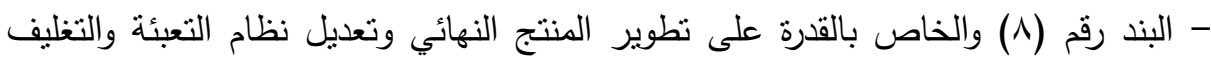

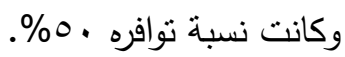
- البند رقم (• () والخاص بالقدرة على الحد من النلوث الخارجي وتحقيق منافع بيئية. وكانت نسبة نوافر •\%.

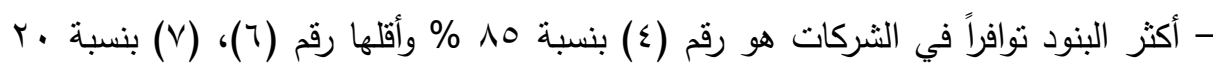
ويستنتج من تلك النتائج الآتي: • أن أغلب الصادرات المصرية قائمة على استهلاك عناصر الميزة النسبية للموارد البيئية الطبيعية (النفط - والخامات الأولية)، ولم تتحول بعد إلى الاعنماد على عناصر الميزات 
التتافسية للصادرات الصناعية والممثلة في الاسعار والجودة (منها الجودة البيئية) والتمايز الفني والتقني المستتد للابتكار .

• أن الصادرات المصرية ستتعرض لهنافسة كبيرة إذا استمرت الأوضاع الحالية لهيكل

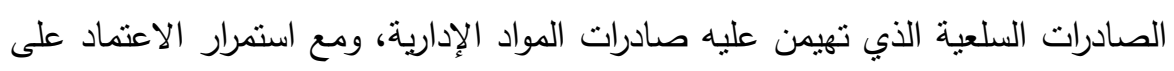

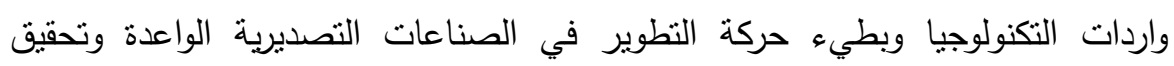
التكامل الاقتصاد العربي. أن تتمية الصادرات المصرية لم تراعي فيها الظروف البيئية الملائكة، نظراً لغياب عناصر تكنولوجيا البيئية، وعدم ملاحقة الأبعاد البيئية للتصدير والمتعلقة بالإدارة البيئية المتكاملة،

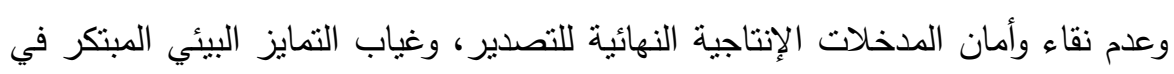
كافة أنواع الصادرات. • أنه على الرغم من أن اغلب الصادرات المصرية غير منوافقة معايير البيئة الاقتصادية

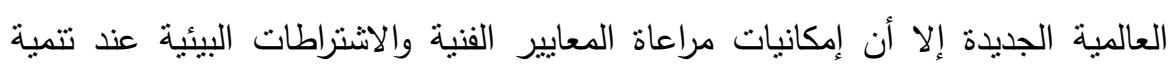

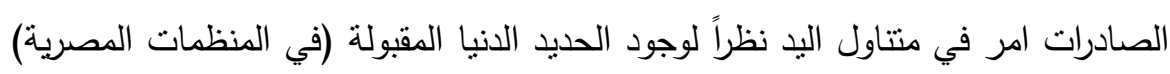
لقيام أنظمة جودة بيئية فعالة، ووجود درجة مناسبة من القدرات على النوافق مع متغيرات النظام التجاري العالمي إذا ما تم النطور بمعدلات أكثر تسارعاً.

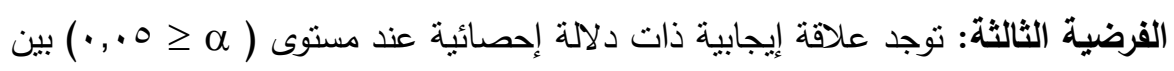

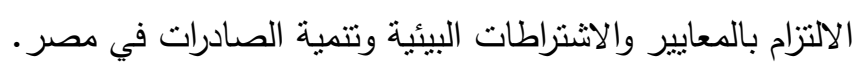
- قد تم اللجوء للمفاضلة بين طرق عديدة لمكافحة وخفض التلوث، وهذا الخفض يمكن تحقيقه من خلال التنظيم وفرض المعايير والاشتراطات البيئية، كما يمكن تحقيقه باستخدام أدوات اقتصادية (على سبيل المثال فرض الضرائب البيئية، التخلي عن استعمال الطاقة

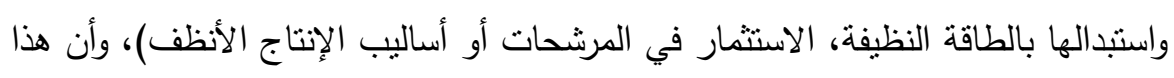

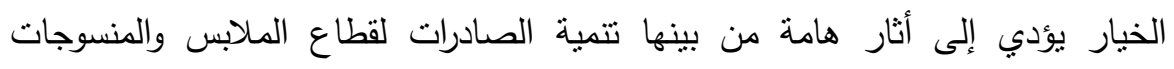
بالمنطقة الصناعية.

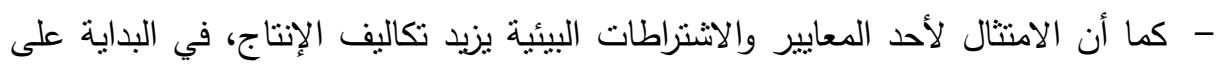
الأقل، عندما يكون على الثركات أن تتكيف مع أحد التغيرات الطارئة على السياسة

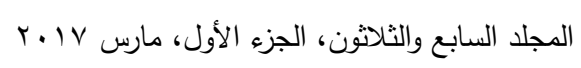


العامة. في هذه الحالة تنتجيب الثركات الهادفة إلى تحقيق أكبر ربح ممكن بأقل تكاليف ممكنة داخل الأسواق التتافسية للتغيرات الحاصلة في التكاليف عبر تعديل القرارات المتعلقة بالإنتاج، بما فيها قيمة أو أنواع المدخلات المستعملة، أو قيمة النواتج المنتجة والمباعة.

- يمكن أن تؤدي الاستجابة إلى التغير في الأنظمة والسياسات المنبعة بشكل عام في الثركات إلى تعديلات في عمليات الإنتاج أو تغييرات في مسنويات الإنتاج إذ يسعى الإسى

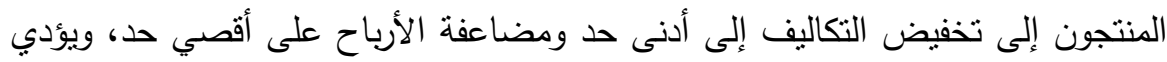
هذا الأمر إلى تغييرات في الصادرات في قطاع الصناعة، ويمكن التخفيف من أثرها بتحقيق مكاسب على صعيد الكفاءة أو تحويل بعض تكاليف الإنتاج الإضافية إلى في المستهلكين المستعدين لدفع ثمن أعلى لقاء منتج ينمتل لأحد المعايير البيائية.

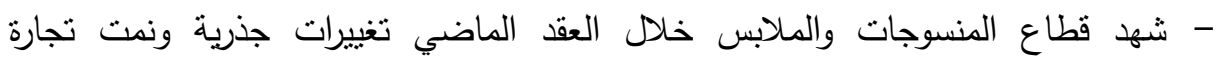
الملابس بمعدلات أسرع بكثير من نمو تجارة المنسوجات، وتتخذ التجارة في هذين القطاعين وجنتن مختلفتين، فصادرات الملابس نكاد نتجه كلها نحو أسواق البلدان المتقدمة، ويمكن أن تتجم عن الأنماط العالمية المتغيرة لمقتضيات السوق والتجارة آثار هامة على المؤسسات التي تعجز عن التكيف سريعاً مع الظروف المتطورة والتي التئي تراعي البعد البيئي باشتراطات ومعاييره التتافسية.

وباستعراض النتائج السابقة، نجد أنه توجد بعض الدراسات التي أكدت ذلك ومنها دراسئه

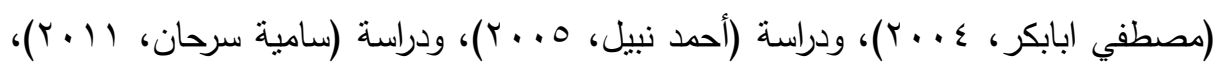

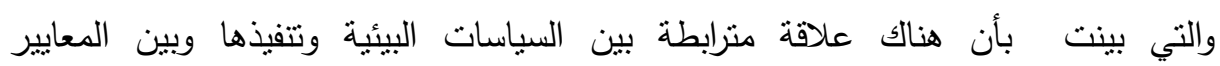
والاشتراطات البيئية إذ أن التطبيق الجاد وبالطرق الأكثر ذكاء يؤدي إلى تتمية القدرات

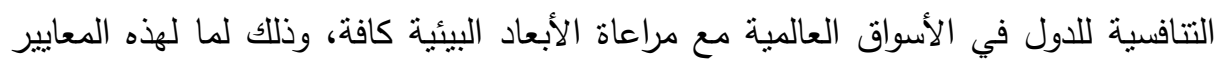

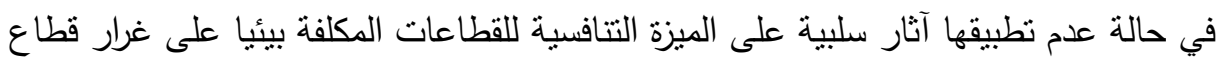
المحروقات والصناعات الأولية التي ترتكز عليها صادرات معظم الدول النامية. وفي الجزئية أدناه من الدراسة بعض الآثار والتي من خلالها أمكن التوصل إلى إلى أنها: 
ا. يمكن للسياسات البيئية من خلال أدواتها خاصة الحوافز الضريبية أن تلعب دوراً هاماً إذا

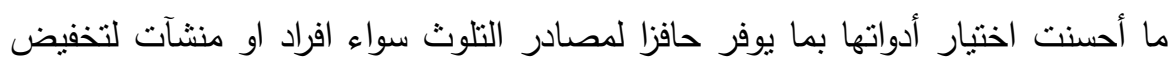

$$
\text { ما يصدر عنها من وحدات تلوث }
$$

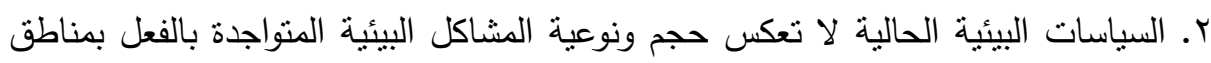
التصدير الحرة وعلى سبيل المثال (مشكلة التخلص الآمن من المخلفات الصلبة - مشكلة

$$
\text { التخلص الآمن من النفايات الخطرة). }
$$

r. التشريعات البيئية الحالية لا تتواكب مع الوتيرة المتسارعة الخاصة بالصناعة مما يؤدى التصى

$$
\text { الى حدوث فجوة كبيرة بين المنصوص عليه في القانون والواقع العملي. }
$$

ع. تعدد الجهات التنفيذية المنوط بها تتفيذ التشريعات البيئية بالإضافة الى عدم التتسيق فيما لئيا

بينها، مما يتطلب زيادة جهود التنسيق لتحقيق التطبيق الفعال للسياسات البيئية.

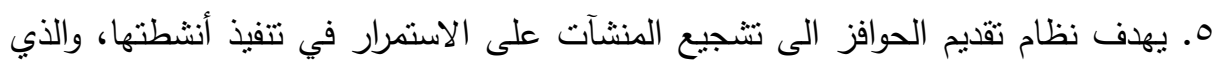

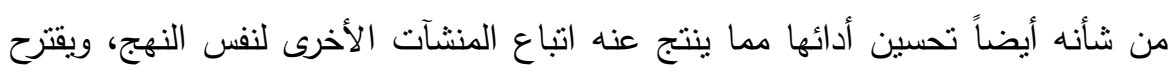

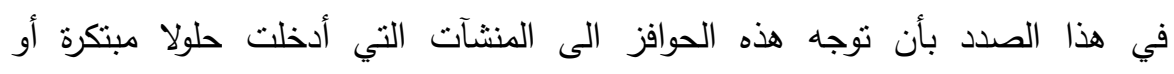
تكنولوجيات مناسبة للتحكم في تأثيراتها البيئية وذلك بناء على معايير تقصر هذه هذه الحوافز على الفئة المتميزة بالفعل.

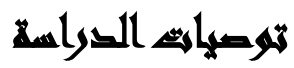

- - دمج مبادئ التتمية المستدامة في سياسات الدولة وبرامجها ومشروعاتها من خلال العمل على إصدار التشريعات وتنبى السياسات التي تتتاسب مع منطلبات النيات النظام التجاري

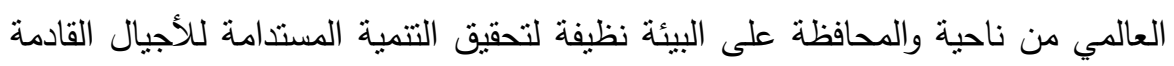

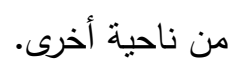
- نشر وزيادة الوعي البيئي وخلق مناخ يشجع الاستثمار في التكنولوجيا النظيفة وعمليات

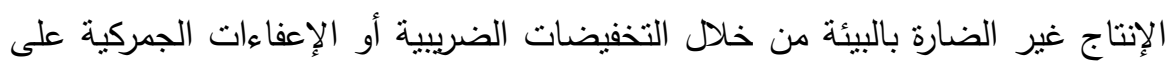

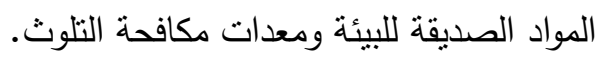


- تفعيل دور منظمة التجارة العالمية والتأكيد على عدم استخدام القيود والمعايير البيئية

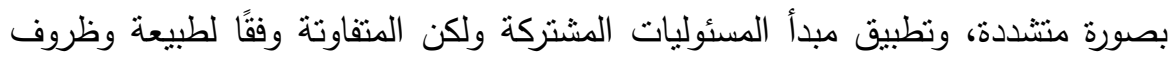
وإمكانيات كل دولة. - تفعيل دور أجهزة الرقابة على الجودة بالاستعانة بما هو متبع في الدول الأوروبية، والأخذ الذان

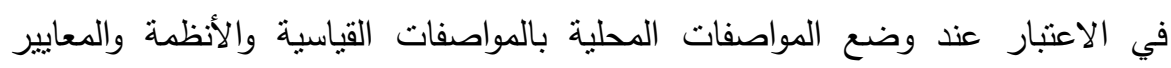
العالمية. - تشجيع الاستثمار الأجنبي في أساليب وتقنيات الإنتاج الأنظف والمشاريع الصديقة للبيئة وإدخال البعد البيئي في السياسات التي تحكم الاستثمارات الأجنبية وسياسات تتمية الصادرات. - دعم دور البحث العلمي والتتمية التكنولوجية وتوفير المناخ الملائم للابتكار وتعزيز فكرة

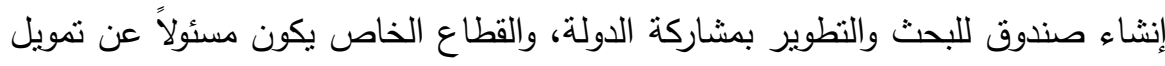
إنشاء وحدات للبحث والنطوير داخل الشركات. - تتويع هيكل الصادرات وتوسيع دائرة التوزيع الجغرافي، وعدم التركيز على توجيه الصادرات لأسواق محددة وفتح أسواق واعدة جديدة. - العمل على حل المشاكل التي تعوق تطور الصناعة من خلال الاهنمام بدأدراسة مشاكل

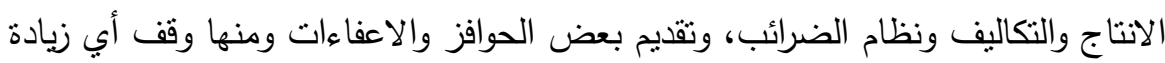
في أسعار الكهرباء والمياه وغيرها من العوامل المساعدة في إنتاج الملابس الجاهزة.

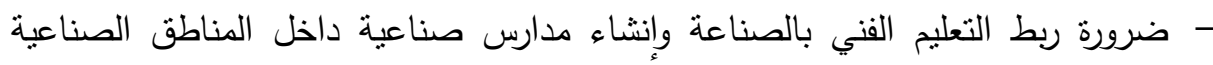
بتخصصات نتاسب نشاط كل منطقة، بمعنى إنثاء المدارس والكليات والمعاهد المتخصصة في تعليم وتدريس صناعة الملابس الجاهزة في مناطق تركز هذه الصناعة. 


\section{المرالمي}

أحمد الجلاد ( ( . ب): التتمية والبيئة في مصر ، دار جهاد للطباعة والنشر والتوزيع، القاهرة.

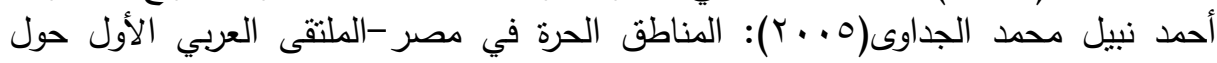

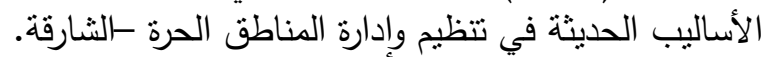

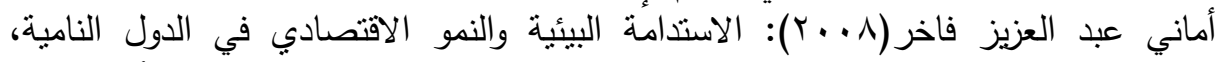

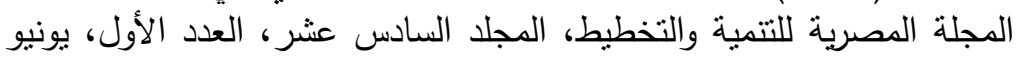

$$
\text { .r... }
$$

تيرباك دينيس(^ . . r): السياسات الوطنية وارتباطها بالمفاوضات حول اتفاق دولي مستقبلي بشأن تغير المناخ - برنامج الأمم المتحدة الإندان الإنمائي.

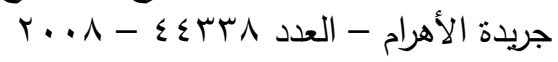

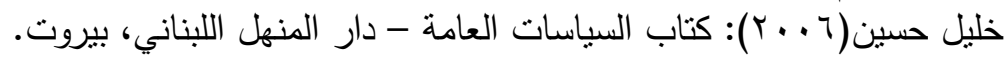

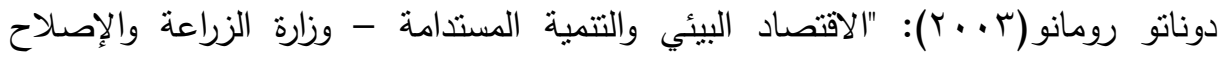

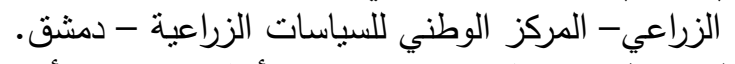

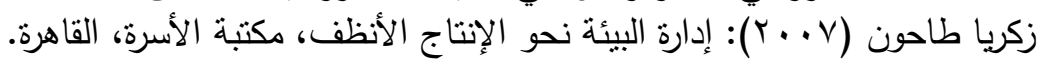

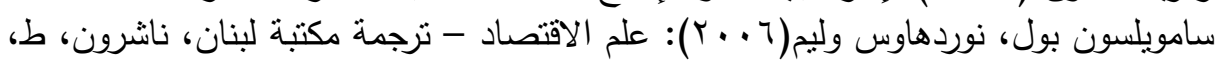

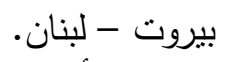

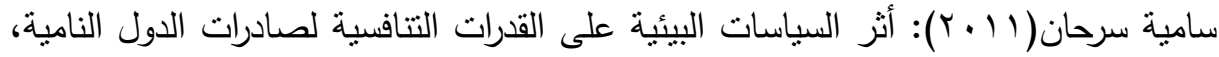

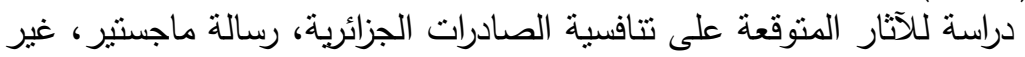

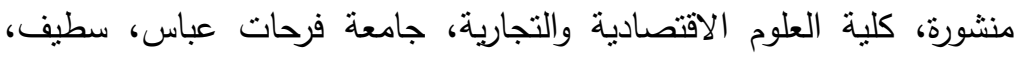

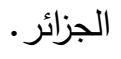

سلوى شعراوي جمعة(997 (1):"صنع السياسات البيئية في مصر" مركز البحوث الاجتماعية، الجامعة الأمريكية بالقاهرة.

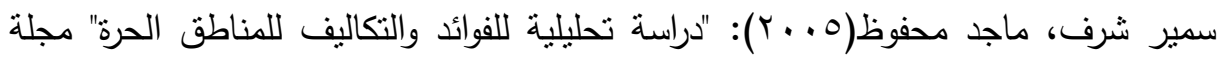

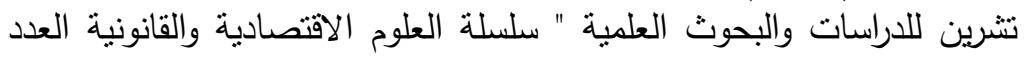

$$
\text { الرابع. }
$$

طارق غلوش(99v (19)):" نحو سياسة اقتصادية مناسبة للحد من التلوث البيئي في البلدان الأقل

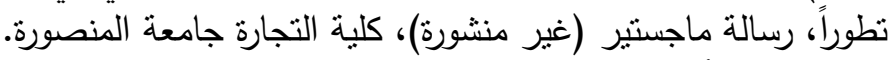

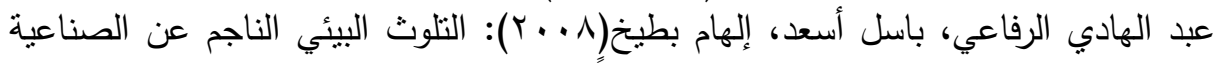

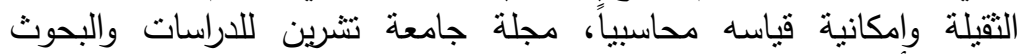

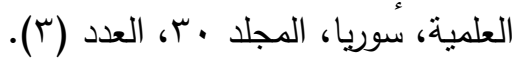

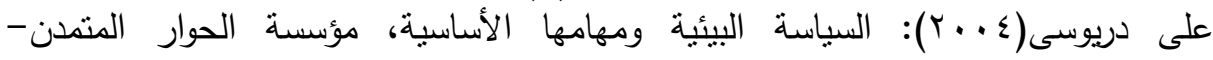

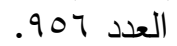

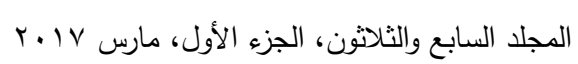




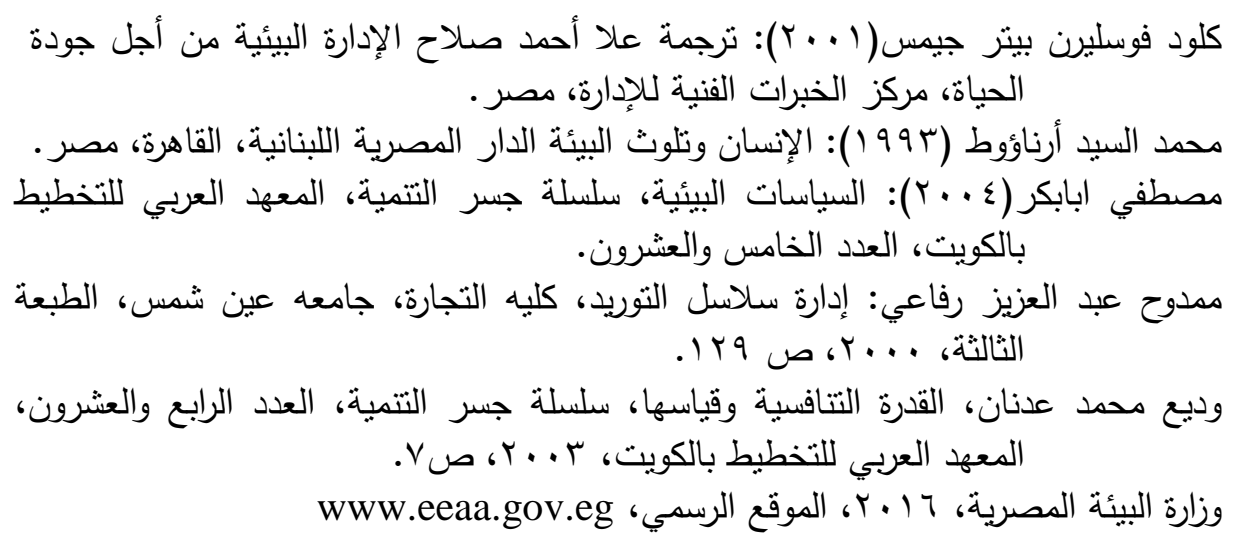

Aiginger K. Competitiveness (2008): from a dangerous obsession to a welfare An OECD Framework for Effective and Efficient Environmental Policies,.

Andersen, M. S. and Massa, I (2000): 'Ecological modernization: origins, dilemmas and future directions', Journal of Environmental Policy and Planning, 337-345.

Andersen, M. S. and Massa, I. 'Ecological modernization: origins, dilemmas and future directions', Journal of Environmental Policy and Planning, (2000): 337-345.

Baumol and Qates, The Theory of Environmental Policy, op-cit. (1995) P.9.

Edum, E, P (1987): "Ecology the link Between the Natural and social Science Hot IRimebart and wino ton, New York, MSA. P. 244.

Lumpkin, G. Thomas, and Gregory G. Dess (2001). "Linking two dimensions of entrepreneurial orientation to firm performance: The moderating role of environment and industry life cycle." Journal of business venturing 16.5 (2001): 429-451.

Porter, Michael E., and Claas Van der Linde (1995). "Toward a new conception of the environment-competitiveness relationship." The journal of economic perspectives 9.4 (1995): 97-118. 
بهاء الدين محمد مرسي وآخرون

\title{
THE IMPACT OF THE IMPLEMENTATION OF THE ENVIRONMENTAL INDUSTRIAL DEVELOPMENT ACHIEVING THE ON POLICIES ANALYTICAL STUDY - FREE ZONE, ISMAILIA
}

\author{
Morsy, B. E. M. ${ }^{(1)}$; Attwa, A. H. ${ }^{(2)}$; Hegi, M. ${ }^{(3)}$ \\ and Ahmed, M. S. ${ }^{(4)}$
}

1) Faculty of Agriculture, Ain Shams University. 2) Ministry of Environment. Cabinet of Ministers 3) Central Laboratory for Agricultural Climate. 4) Cabinet of Ministers

\begin{abstract}
This study aims to assessing the effective role that Environmental Policies play in achieving the industrial development through working inside free export zones, which occupied a major space of economists and politicians concerns whether in the developed or developing countries. These zones were established to attract, localize investments and as they considered one of economic development priorities. Due to the intensive competition that the world witnesses, it was necessary for all different types of organizations to find a shelter that protect them from the storms of change that characterizes the global market.

This study reveals that the existence and sustainability of industrial organizations depend mainly on their commitment with applying the environmental policies through adopting the principle of preventing pollution at its source. Accordingly, the industrial organization endeavors to assess its current environmental position, adopts techniques of green production technologies, takes over polices of energy and resources rationalization, minimizing emits and pollutants. In addition to, using measures that target reducing the flow of wastes to increase recyclability, achieve competitiveness and access to global markets.
\end{abstract}

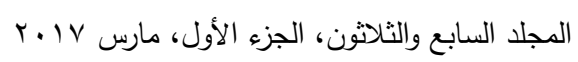


It was revealed after studying the impact of current Environmental Policies that they don't reflect the quantity and quality of environmental issues already existed inside the free export zones, some of which, (Safe disposal of hazardous wastes and Solid wastes). As well as, the current environmental legislations don't keep pace with the continuous acceleration occurred in industrial development, which leads to a significant gap between what is stipulated in the law and the real practice. 